\title{
Adding four-dimensional data assimilation by analysis nudging to the Model for Prediction Across Scales - Atmosphere (version 4.0)
}

\author{
Orren Russell Bullock Jr. ${ }^{1}$, Hosein Foroutan ${ }^{2}$, Robert C. Gilliam ${ }^{1}$, and Jerold A. Herwehe ${ }^{1}$ \\ ${ }^{1}$ Computational Exposure Division, National Exposure Research Laboratory, Office of Research and Development, U.S. \\ Environmental Protection Agency, Research Triangle Park, NC, USA \\ ${ }^{2}$ Department of Biomedical Engineering and Mechanics, Virginia Polytechnic Institute and State University, \\ Blacksburg, VA, USA
}

Correspondence: Orren Russell Bullock Jr. (bullock.russell@epa.gov)

Received: 5 October 2017 - Discussion started: 22 December 2017

Revised: 20 June 2018 - Accepted: 28 June 2018 - Published: 16 July 2018

\begin{abstract}
The Model for Prediction Across Scales - Atmosphere (MPAS-A) has been modified to allow fourdimensional data assimilation (FDDA) by the nudging of temperature, humidity, and wind toward target values predefined on the MPAS-A computational mesh. The addition of nudging allows MPAS-A to be used as a global-scale meteorological driver for retrospective air quality modeling. The technique of "analysis nudging" developed for the Penn State/National Center for Atmospheric Research (NCAR) Mesoscale Model, and later applied in the Weather Research and Forecasting model, is implemented in MPAS-A with adaptations for its polygonal Voronoi mesh. Reference fields generated from $1^{\circ} \times 1^{\circ}$ National Centers for Environmental Prediction (NCEP) FNL (Final) Operational Global Analysis data were used to constrain MPAS-A simulations on a $92-25 \mathrm{~km}$ variable-resolution mesh with refinement centered over the contiguous United States. Test simulations were conducted for January and July 2013 with and without FDDA, and compared to reference fields and near-surface meteorological observations. The results demonstrate that MPAS-A with analysis nudging has high fidelity to the reference data while still maintaining conservation of mass as in the unmodified model. The results also show that application of FDDA constrains model errors relative to $2 \mathrm{~m}$ temperature, $2 \mathrm{~m}$ water vapor mixing ratio, and $10 \mathrm{~m}$ wind speed such that they continue to be at or below the magnitudes found at the start of each test period.
\end{abstract}

\section{Introduction}

Combining data at various times in a dynamical model to provide time continuity and dynamic balance among the model fields was first suggested by Charney et al. (1969) and has become known as four-dimensional data assimilation (FDDA). Nudging, also known as Newtonian relaxation, involves the use of special terms in forecast equations to "nudge" an atmospheric model simulation toward observations or some reference state. It was originally employed for dynamic initialization (Anthes, 1974; Hoke and Anthes, 1976). Many approaches to data assimilation have been developed for dynamical atmospheric models including simple interpolation and more complex variational and stochastic methods. However, these have usually been intended to initialize prognostic models. Nudging was tested as a means for improving diagnostic simulations by Stauffer and Seaman (1990) in the Penn State/National Center for Atmospheric Research (NCAR) Mesoscale Model - version 4 (MM4) (Anthes et al., 1987). In that study, nudging was applied in two ways. The model solutions were nudged toward either gridded analyses ("analysis nudging") or individual observations ("obs nudging"). After MM4, both forms of nudging were implemented in its successor MM5 (Grell et al., 1995) and subsequently in the Weather Research and Forecasting (WRF) model (Skamarock and Klemp, 2008).

In addition to basic variables like temperature, humidity, wind, cloud cover, and precipitation, meteorological simulations guided by nudging provide factors critical to air quality modeling that are not easily observed, such as stability, turbulence, mixing height, etc. Nudging applied in MM4, MM5, 
and WRF has been used at the U.S. Environmental Protection Agency (U.S. EPA) for almost three decades to support air quality modeling, first with the Regional Acid Deposition Model (RADM) (Chang et al., 1987) and continuing to the present day with the Community Multiscale Air Quality (CMAQ) model (Byun and Schere, 2006; Appel et al., 2017).

It has long been recognized that air quality at any particular location can be affected by pollution sources on local to global scales (NRC, 1998, 2010). Air quality models are often applied with relatively coarse horizontal resolution on hemispheric and global scales to provide boundary information for nested, higher-resolution regional models (Bullock Jr. et al., 2008; Jacobson and Ginnebaugh, 2010; Schere et al., 2012; Mathur et al., 2014). In various applications, this nested modeling strategy has created unrealistic simulations at the lateral boundaries of internal model domains due to discontinuities in horizontal and vertical resolution and/or differing modeling assumptions between separate models used at each scale (Warner et al., 1997; Bullock Jr. et al., 2009; Tudor and Termonia, 2010; Mathur et al., 2017).

To address the need for a global-to-local air quality modeling system that can avoid boundary problems associated with model domain nesting, this work adapts the Model for Prediction Across Scales - Atmosphere (MPAS-A) (Skamarock et al., 2012) for use as the meteorological component of a future coupled meteorological-chemical modeling system. MPAS-A, which features a global computational mesh based on a centroidal Voronoi tessellation (Du et al., 1999), offers gradual mesh refinement rather than discrete nesting to a focal region. For retrospective air quality modeling, an FDDA approach based on analysis nudging has been developed and tested in MPAS-A as described below.

\section{Experimental design, implementation, and testing}

FDDA by way of analysis nudging, similar to that described in Stauffer and Seaman (1990), has been added to MPASA. Unlike MM4, MM5, and WRF, which are limited-area models with rectangular computational grids, MPAS-A has a polygonal computational mesh as illustrated in Fig. 1. Nonetheless, once the required "target" fields (i.e., reference data for nudging) are defined to match the MPAS-A prognostic variable array, analysis nudging in MPAS-A is similar to its ancestral implementations.

\subsection{Description of analysis nudging in MPAS-A}

Analysis nudging is applied in MPAS-A by the addition of a nudging tendency term to the normal predictive equation. The nudging tendency for prognostic variable $\alpha$ is calculated as

$\left(\frac{\partial \alpha}{\partial t}\right)_{\text {nudge }}=G_{\alpha} W_{\mathrm{PBL}} W_{\text {layer }}\left(\alpha_{\text {target }}-\alpha\right)$,

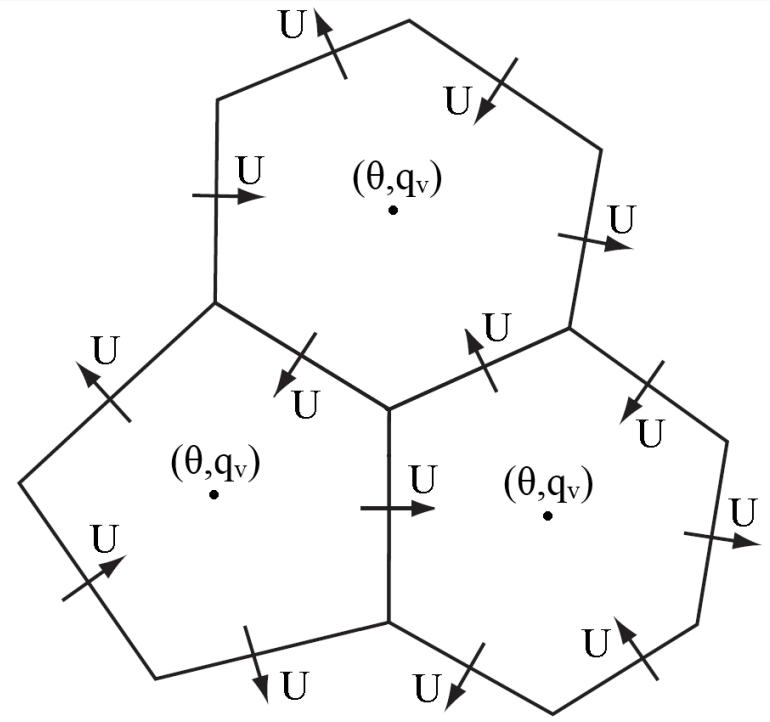

Figure 1. A schematic of C-grid staggered variables on the MPASA horizontal mesh. Normal wind velocities $(U)$ are defined on the cell faces while all other scalar variables are defined at the cell centers, including potential temperature $(\theta)$ and water vapor mixing ratio $\left(q_{\mathrm{v}}\right)$.

where $G_{\alpha}$ is a nudging inverse timescale or "nudging coefficient", $W_{\mathrm{PBL}}$ and $W_{\text {layer }}$ are special binary terms ( 1 or 0$)$, and $\alpha_{\text {target }}$ is the target or reference value for $\alpha$. Trusted reference fields are typically only available at certain times each day and temporal interpolation is required to provide target values at each model time step. It may be advantageous to avoid nudging in the planetary boundary layer (PBL) so as not to disrupt simulated diurnal processes. In this case, $W_{\mathrm{PBL}}$ can be set equal to 1 in layers above the simulated PBL top and set equal to 0 in layers below or containing the PBL top. Otherwise, $W_{\mathrm{PBL}}$ can be set equal to 1 in all layers. $W_{\text {layer }}$ is a similar binary term to allow the exclusion of nudging near the surface based simply on vertical layer number. $G_{\alpha}$, $W_{\mathrm{PBL}}$, and $W_{\text {layer }}$ are all defined independently for each of the nudged variables.

Analysis nudging has been applied for potential temperature $(\Theta)$, water vapor mixing ratio $\left(q_{\mathrm{v}}\right)$, and wind. Treating wind involves extra complications because of the way it is represented in the MPAS-A mesh. As illustrated by Fig. 1, scalar prognostic variables including $\Theta$ and $q_{\mathrm{v}}$ are defined at the cell centers. However, the prognostic variable for wind in MPAS-A is the component perpendicular to the cell faces $(U)$. To nudge wind, meridional and zonal decompositions at the cell centers are used. These model variables UReconstructZonal and UReconstructMeridional already exist to treat the influence of parameterized convection and PBL processes on the wind field. While the wind component across cell edges $(U)$ could be nudged directly, this method would require $50 \%$ more comparisons between prognostic and target values since there are 3 times as many cell edges as 
Table 1. MPAS-A non-default namelist configuration variables used for testing (except physics).

\begin{tabular}{ll}
\hline nhyd_model & \\
\hline config_dt & Model time step, in seconds \\
& Applied value: 150.0 \\
config_start_time & Starting time for model run \\
& Applied value: “2013-01-01_00:00:00” and “2013-07-01_00:00:00” \\
config_run_duration & Length of model run \\
& Applied value: “31_00:00:00” \\
config_len_disp & Horizontal length scale for Smagorinsky formulation of horizontal diffusion \\
& Applied value: 25000.0 \\
config_h_ScaleWithMesh & Scale eddy viscosities with mesh-density function for horizontal diffusion \\
& Applied value: .true. \\
\hline damping & \\
\hline config_zd & Height MSL to begin w-damping profile \\
config_xnutr & Applied value: 27000.0 \\
& Maximum w-damping coefficient at model top \\
& Applied value: 0.2 \\
\hline
\end{tabular}

there are cells. Nudging tendencies for UReconstructZonal and UReconstructMeridional are translated to cell edges in the same manner as the tendencies for PBL and convection processes.

\subsection{Creating target fields}

The MPAS-A modeling system already provides model initialization software, namely the executable program init_atmosphere_model. For this study, initialization fields were created at each time where nudging target fields were desired using $1^{\circ} \times 1^{\circ}$ National Centers for Environmental Prediction (NCEP) FNL (Final) Operational Global Analysis data (ds083.2) (NCEP/NWS/NOAA/U.S. Department of Commerce, 2000). Target fields could be based on other analytical methods such as three- and four-dimensional variational assimilation (3D-Var, 4D-Var) or an ensemble Kalman filter (EnKF). However, the NCEP FNL data are already produced using techniques similar to 4D-Var. A full description of the NCEP FNL data product is available from the "Documentation" tab at https://doi.org/10.5065/D6M043C6. The spatial resolution of the $1^{\circ} \times 1^{\circ}$ NCEP FNL data approximates that of the coarse portion of the MPAS-A mesh used in this study. The nudged variables $\Theta, q_{\mathrm{v}}$, UReconstructZonal, and UReconstructMeridional were extracted from each initialization file, renamed $t h \_f d d a \_n e w, q v \_f d d a \_n e w$, $u \_f d d a \_n e w$, and $v_{-} f d d a \_n e w$, respectively, and used to compile the necessary FDDA input files. The modified MPAS-A reads in new FDDA targets every $6 \mathrm{~h}$ when NCEP FNL data are available, specifically at 00:00, 06:00, 12:00, and 18:00 UTC. Target values at intervening times during the simulation are computed using linear time interpolation.

The FDDA target variable names contain "new" to indicate that, for the time increment at which they are read, the val- ues represent the target value at the end of the upcoming $6 \mathrm{~h}$ FDDA time interval. Unlike WRF which reads in "old" and "new" targets for each FDDA interval, the modified MPAS-A reads only "new" values. The "new" values from the previous time interval are recycled to be used as the "old" values, thus reducing the FDDA target file size by half. At simulation start time, initial values for $\Theta, q_{\mathrm{v}}$, UReconstructZonal, and UReconstructMeridional are used to set $t h \_f d d a \_o l d, q v_{-} f d d a_{-}$ $o l d, u \_f d d a \_o l d$, and $v \_f d d a \_o l d$, respectively. Thus, simulation start time must be at 00:00, 06:00, 12:00, or 18:00 UTC in order to maintain the $6 \mathrm{~h}$ FDDA data interval.

Scripts have been written to automate the process of running init_atmosphere_model for each FDDA time, extracting the four nudged variables, and composing the FDDA target input file. They perform variable extraction and FDDA input file composition using NetCDF Operators (NCO) software available at http://nco.sourceforge.net/ (last access: 9 July 2018).

\subsection{FDDA test applications}

MPAS-A version 4.0 (https://github.com/MPAS-Dev/ MPAS-Release/releases/tag/v4.0, last access: 9 July 2018), modified to include FDDA by analysis nudging as described above, was applied on a $92-25 \mathrm{~km}$ variable-resolution mesh obtained from the MPAS-A mesh downloads page (http://www2.mmm.ucar.edu/projects/mpas/atmosphere_ meshes/x4.163842.tar.gz, last access: 9 July 2018) with the origin of this mesh repositioned to $40^{\circ} \mathrm{N}, 95^{\circ} \mathrm{W}$. Two test simulation periods were defined spanning January and July 2013.

As mentioned before, model initialization and FDDA inputs were produced from $1^{\circ} \times 1^{\circ}$ NCEP FNL data using the init_atmosphere_model software included in the 
Table 2. Standard MPAS-A physics namelist variables used for testing.

\begin{tabular}{|c|c|}
\hline config_sst_update & $\begin{array}{l}\text { Logical used to update the sea surface temperatures (SSTs) and fractional sea ice. If set to true, SSTs } \\
\text { are updated using the file config_sfc_update_name. If set to false, SSTs remain fixed during the entire } \\
\text { model run. } \\
\text { Applied value: .true. }\end{array}$ \\
\hline config_sstdiurn_update & $\begin{array}{l}\text { If set to true, a diurnal cycle is applied to the SSTs. If set to false, SSTs remain constant during the } \\
\text { entire day. } \\
\text { Applied value: false. (same as default value) }\end{array}$ \\
\hline config_deepsoiltemp_update & $\begin{array}{l}\text { If set to true, deep soil temperatures are slowly updated during the model run. If set to false, deep soil } \\
\text { temperatures remain fixed during the entire run. } \\
\text { Applied value: false. (same as default value) }\end{array}$ \\
\hline config_radtlw_interval & $\begin{array}{l}\text { Temporal interval between calls to the parameterizations of longwave radiation, format "yyyy-mm- } \\
\text { dd_hh:mm:ss". } \\
\text { Applied value: "00:10:00" }\end{array}$ \\
\hline config_radtsw_interval & $\begin{array}{l}\text { Temporal interval between calls to the parameterizations of shortwave radiation, format "yyyy-mm- } \\
\text { dd_hh:mm:ss". } \\
\text { Applied value: "00:10:00" }\end{array}$ \\
\hline config_bucket_update & $\begin{array}{l}\text { Temporal interval between updates to restoring the accumulated rain and radiation fields below their } \\
\text { respective bucket values, format "yyyy-mm-dd_hh:mm:ss". } \\
\text { Applied value: "none" (same as default value) }\end{array}$ \\
\hline config_physics_suite & $\begin{array}{l}\text { Physics suite: } \\
\text { Not applicable. }\end{array}$ \\
\hline config_microp_scheme & $\begin{array}{l}\text { Cloud microphysics scheme: } \\
\text { Applied value: "wsm6" }\end{array}$ \\
\hline config_convection_scheme & $\begin{array}{l}\text { Convection scheme: } \\
\text { Applied value: "kain_fritsch" }\end{array}$ \\
\hline config_lsm_scheme & $\begin{array}{l}\text { Land-surface scheme: } \\
\text { Applied value: "noah" }\end{array}$ \\
\hline config_pbl_scheme & $\begin{array}{l}\text { Planetary boundary layer scheme: } \\
\text { Applied value: "ysu”" }\end{array}$ \\
\hline config_radt_cld scheme & $\begin{array}{l}\text { Parameterization of cloud fraction for long- and shortwave radiation schemes: } \\
\text { Applied value: "cld_fraction" }\end{array}$ \\
\hline config_radt_lw_scheme & $\begin{array}{l}\text { Longwave (LW) radiation scheme: } \\
\text { Applied value: "rrtmg_lw" }\end{array}$ \\
\hline config_radt_sw_scheme & $\begin{array}{l}\text { Shortwave }(\mathrm{SW}) \text { radiation scheme: } \\
\text { Applied value: "rrtmg_sw" }\end{array}$ \\
\hline config_sfclayer_scheme & $\begin{array}{l}\text { Surface-layer scheme: } \\
\text { Applied value: "monin-obukhov" }\end{array}$ \\
\hline
\end{tabular}

MPAS-A version 4.0 public distribution. For this study, init_atmosphere_model was slightly modified to allow finer vertical resolution near the surface. Air quality models typically require fine vertical resolution in the PBL in order to better simulate pollutant emissions which are commonly near the surface. To produce sufficiently thin layers near the surface, the unmodified init_atmosphere_model required an unreasonable number of layers due to the 1.5 -power function used to define layer boundary heights. Modified Fortran code described in Appendix A was developed such that only 50 layers were required with the model top specified at $30 \mathrm{~km}$. Using the modified code and given a surface elevation at sea level, layer thickness is $18 \mathrm{~m}$ at the bottom, $232 \mathrm{~m}$ at $1.5 \mathrm{~km}$ elevation, $1000 \mathrm{~m}$ at $12.5 \mathrm{~km}$ elevation, and $1729 \mathrm{~m}$ at the top. This layer structure was used to produce model ini- tialization and FDDA target data files for all MPAS-A model simulations described below.

The modified init_atmosphere_model was also used to produce update fields for sea surface temperature and sea ice at $6 \mathrm{~h}$ intervals throughout each test period. For this purpose, the new layer generation function had no bearing, but a problem was discovered in the original MPAS-A model code where sea ice was being analyzed over land areas. This problem was solved with additional code modifications described in Appendix B.

Once the required initialization, surface update, and FDDA target fields were in place, MPAS-A simulations were performed with the atmosphere_model program. Table 1 shows all non-default nhyd_model and damping namelist options used in this study. Namelist options for atmosphere_model from the standard MPAS-A 
Table 3. New MPAS-A physics namelist variables added for the FDDA implementation and the values used for testing.

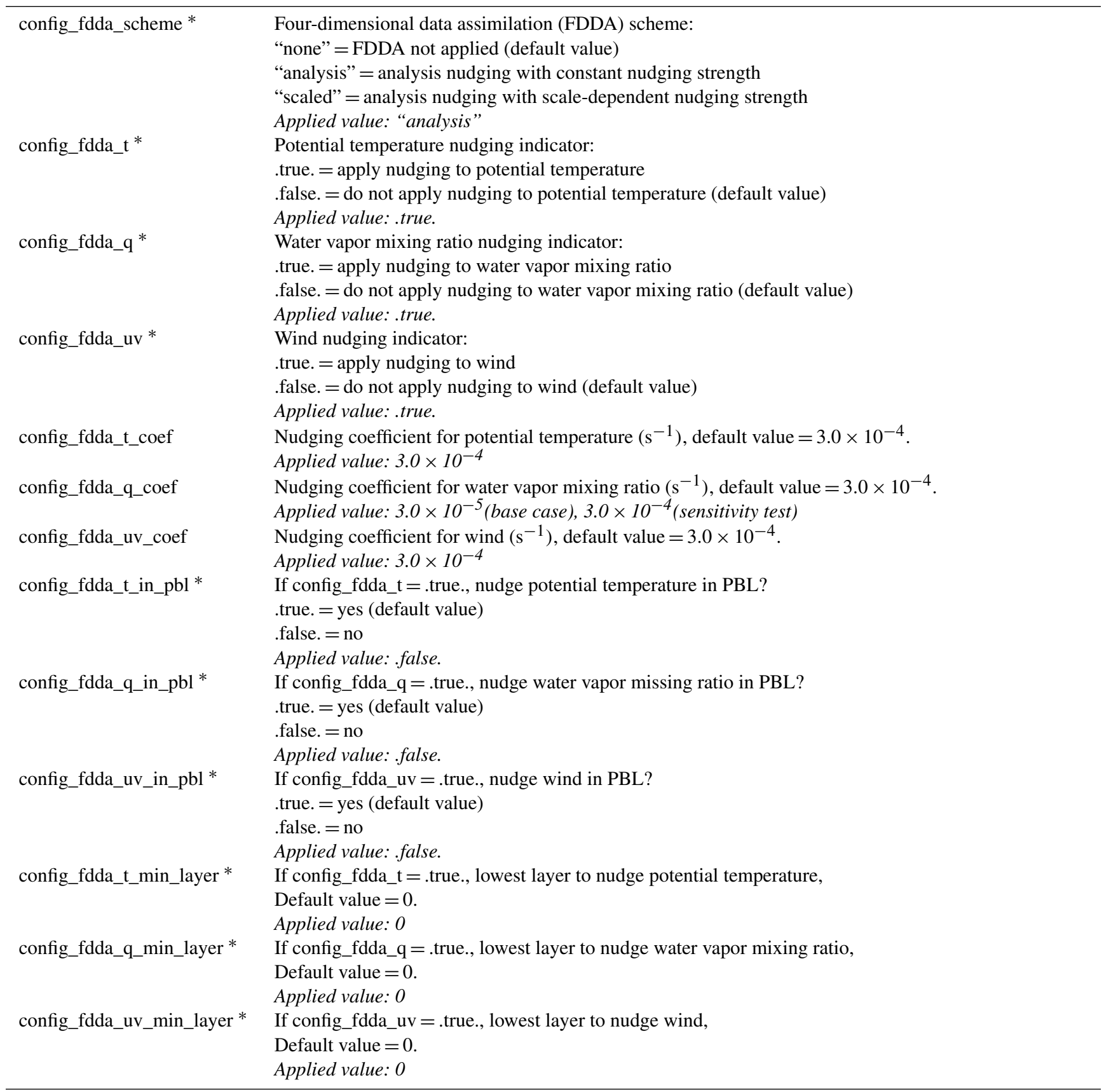

and their default values are described in Appendix B of the MPAS - Atmosphere model user's guide version 4.0 (available at http://www2.mmm.ucar.edu/projects/mpas/ mpas_atmosphere_users_guide_4.0.pdf, last access: 9 July 2018). Table 2 shows all applicable physics namelist options chosen from the standard MPAS list. These do not include namelist options added to MPAS-A as part of the FDDA implementation.

Table 3 shows the new namelist options added as part of the FDDA implementation and the values used for test- ing in this study. These options are similar to those used in the WRF model for FDDA application. WRF contains them within a special $f d d a$ subset of namelist options. For now, they have been added to the physics namelist input variable list for MPAS-A. The primary option to invoke FDDA is config_fdda_scheme. As a default, config_fdda_scheme $=$ off, and FDDA is not invoked in the modified MPAS-A model. If FDDA is invoked with a value of analysis, then the other options in Table 3 become applicable. The modified MPAS-A code also includes a second option for FDDA called scaled 

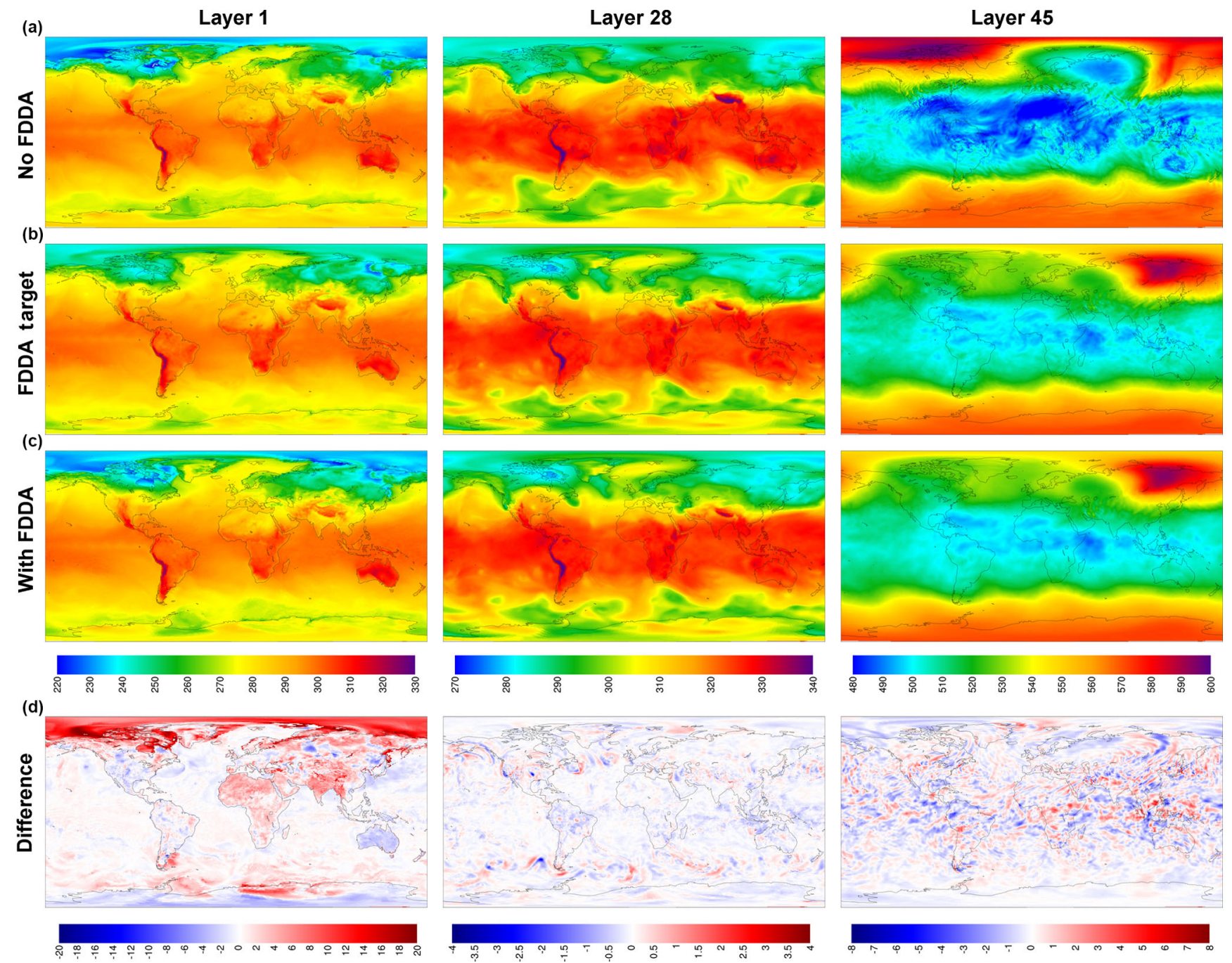

Figure 2. MPAS-A simulation results without FDDA (a), FDDA target fields (b), MPAS-A results with FDDA (c), and FDDA target minus MPAS-A with FDDA (d) for potential temperature (K) in layers 1, 28, and 45, for 00:00 UTC on 11 January 2013, 10 days into the simulation.

which allows the user to adjust nudging strength based on MPAS cell size. This option is still under development and has not been investigated as a part of this study.

FDDA can be selectively applied or omitted for each meteorological variable $\left(\Theta, q_{\mathrm{v}}, U\right)$. If applied, the nudging strength is controlled by a variable-specific nudging coefficient. FDDA for each variable can be applied throughout all vertical layers, or only above a particular layer number. In many previous applications of WRF, it was common for FDDA to only be applied above the PBL so as not to disrupt the diurnal evolution of the PBL with data from a linear time interpolation (Otte et al., 2012; Bowden et al., 2012, 2013; Bullock Jr. et al., 2014). Table 3 shows namelist options provided to avoid nudging in the PBL, avoid nudging below a specified layer number, or both. It is also worth noting here that the default nudging coefficients implemented in MPAS-A are equal to $3.0 \times 10^{-4} \mathrm{~s}^{-1}$ for all variables, just like in WRF. The theoretical reasoning comes from Stauffer and Seaman (1990) where they equate this nudging timescale to that of meteorological phenomena at the meso- $\alpha$ spatial scale. Unlike for temperature and wind, nudging water vapor concentration perturbs atmospheric mass in the simulation. Previous studies using WRF have chosen to employ smaller nudging coefficients for $q_{\mathrm{v}}$ versus other variables (Otte et al., 2012; Bowden et al., 2012, 2013; Bullock Jr. et al., 2014). Results discussed later in this work show some benefit from doing so. For this study, the nudging coefficient for $q_{\mathrm{v}}$ was 1 order of magnitude smaller than that for the other variables, except for a special test where the value was kept equal.

\section{Results}

To evaluate FDDA in MPAS-A, test simulations for January and July of 2013 were performed with both the standard 

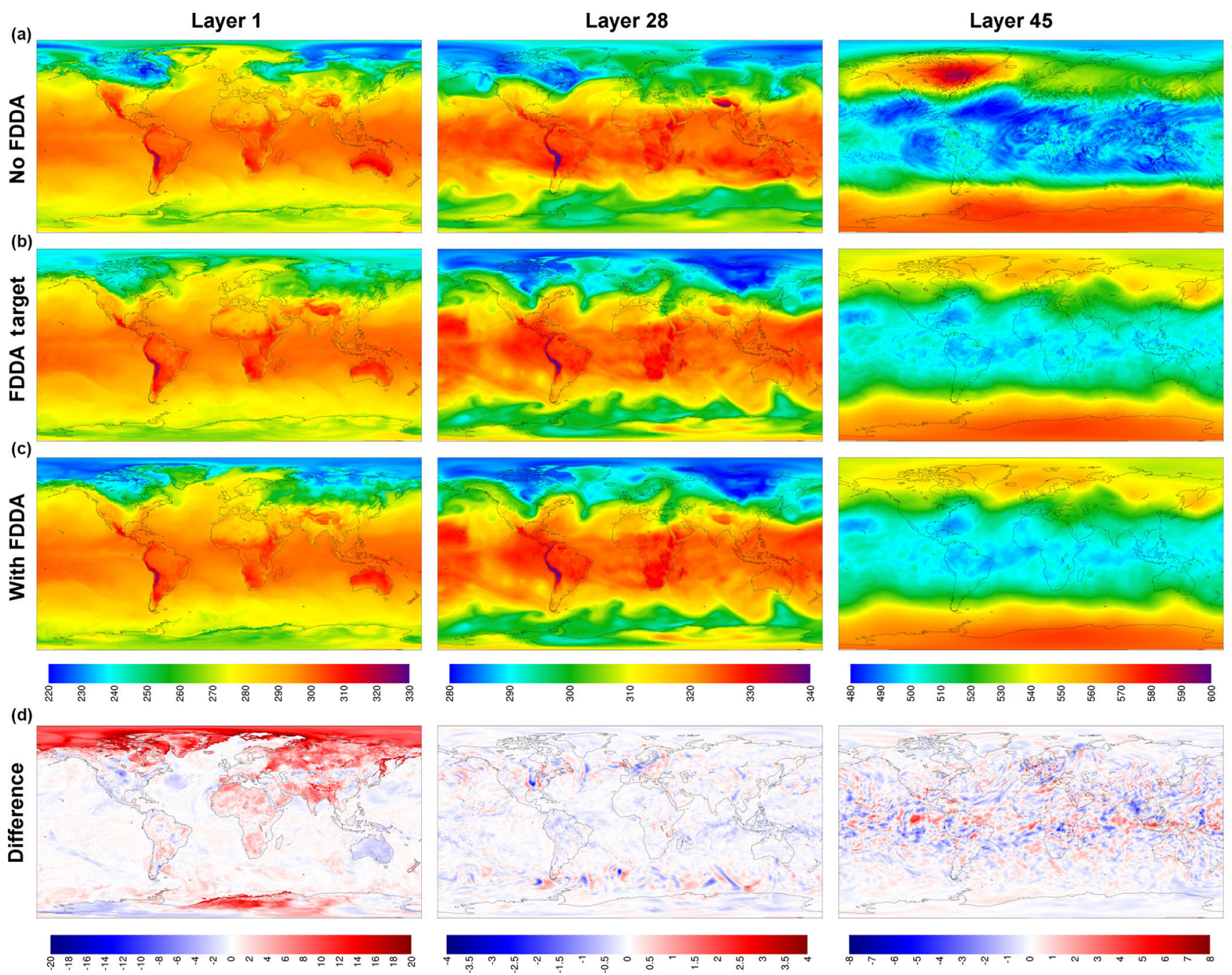

Figure 3. MPAS-A simulation results without FDDA (a), FDDA target fields (b), MPAS-A results with FDDA (c), and FDDA target minus MPAS-A with FDDA (d) for potential temperature (K) in layers 1, 28, and 45, for 00:00 UTC on 31 January 2013, 30 days into the simulation.

version of the model and the modified model using FDDA by analysis nudging. The modified MPAS-A was also applied with FDDA turned off to verify agreement with the results obtained from the standard model. Model results from the standard and modified versions were first compared to the FDDA target fields. Obviously, nudging strongly toward the target fields should produce good agreement with those fields. The intent of these first comparisons was to verify that using nudging coefficients for temperature, humidity, and wind similar to those used in WRF would constrain MPASA simulations in a reasonable manner. To further test the capabilities of FDDA in MPAS-A, simulated surface-level data for temperature, humidity, and wind speed from both the standard and modified MPAS-A models were then compared to observational data from the Meteorological Assimilation Data Ingest System (MADIS) (https://madis.noaa.gov, last access: 9 July 2018). Finally, total dry air, total water va- por, and total atmospheric mass calculations were performed to test for any corruption of mass conservation by the implementation of FDDA in MPAS-A.

\subsection{Comparisons to FDDA target fields}

Figure 2 shows MPAS-A simulation results and FDDA target fields for potential temperature in layers 1, 28, and 45, for 00:00 UTC, 11 January 2013, 10 days into the simulation. The left column of maps shows layer 1 values from the standard MPAS-A (Fig. 2a), the FDDA target field (Fig. 2b), MPAS-A with FDDA applied (Fig. 2c), and the difference field (Fig. 2d). Differences are calculated as FDDA target field minus MPAS-A with FDDA to reflect the polarity of the nudging force. The center and right columns show the same information for layers 28 and 45, respectively. Layer 1 extends from 0 to $\sim 18 \mathrm{~m}$ above the surface where the surface is at mean sea level (m.s.l.), and to $\sim 15 \mathrm{~m}$ above the 


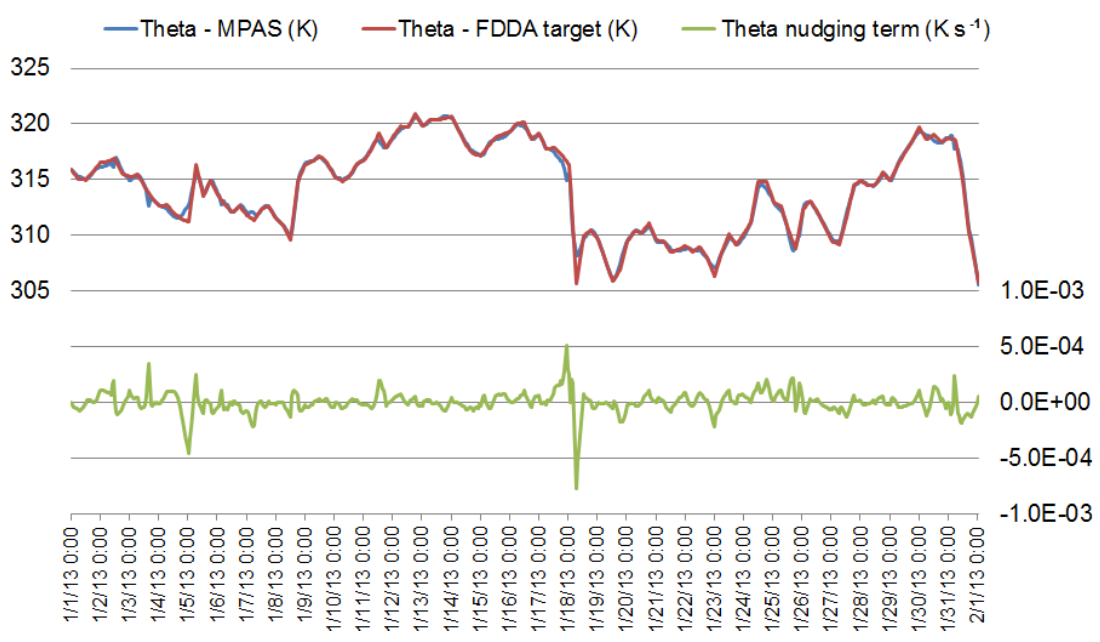

Figure 4. Timeline analysis for January 2013 showing simulated potential temperature (blue line), the potential temperature target value (red line), and the nudging term arising from their discrepancy (green line) for layer 28 of the MPAS cell containing Research Triangle Park, NC (cell center location $35.93^{\circ} \mathrm{N}, 78.96^{\circ} \mathrm{W}$ ). Dates are indicated in $\mathrm{mm} / \mathrm{dd} / \mathrm{yy}$ format.
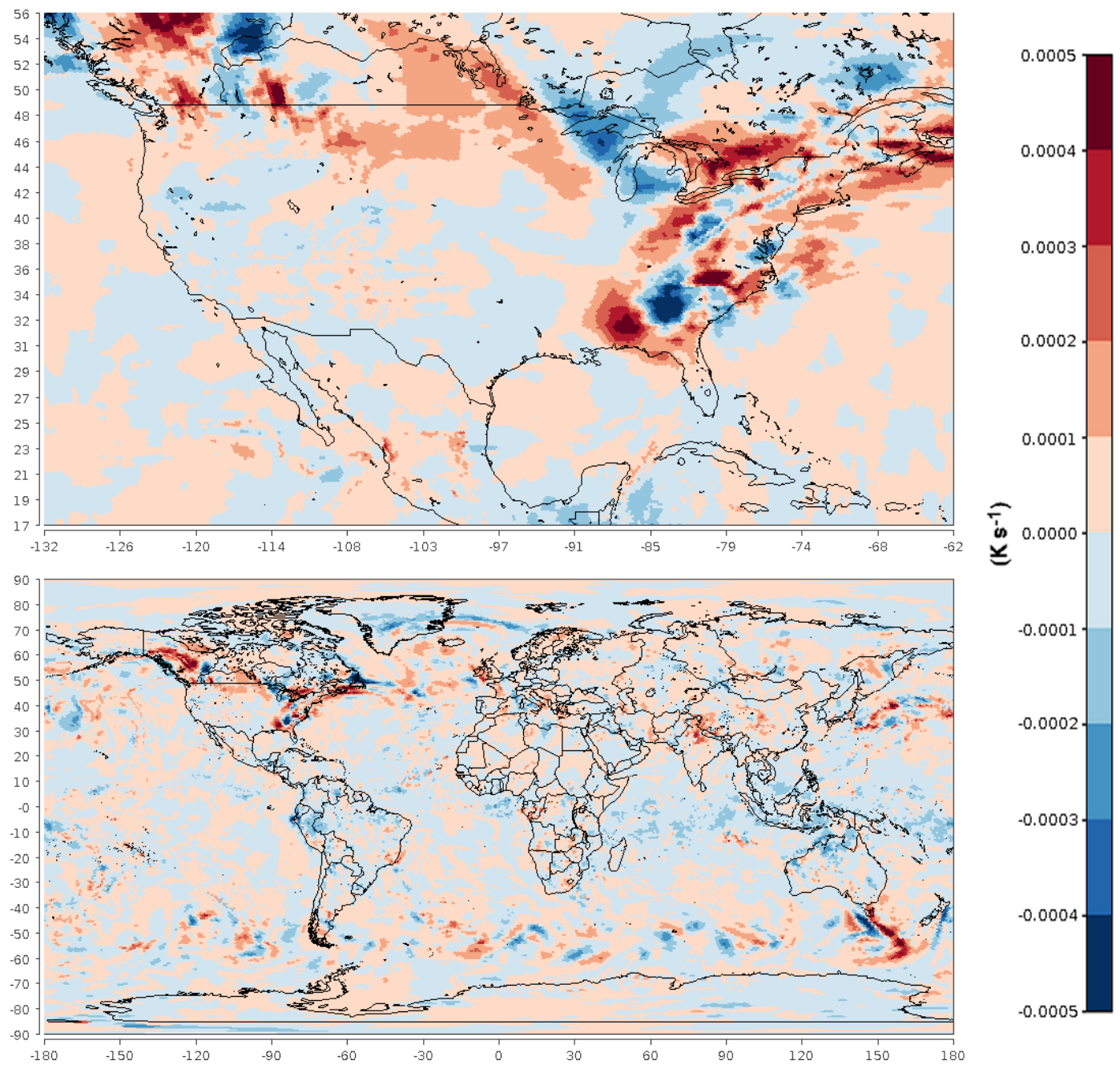

Figure 5. Spatial plots of the nudging term for potential temperature in layer 28 at 00:00 UTC on 18 January 2013. 

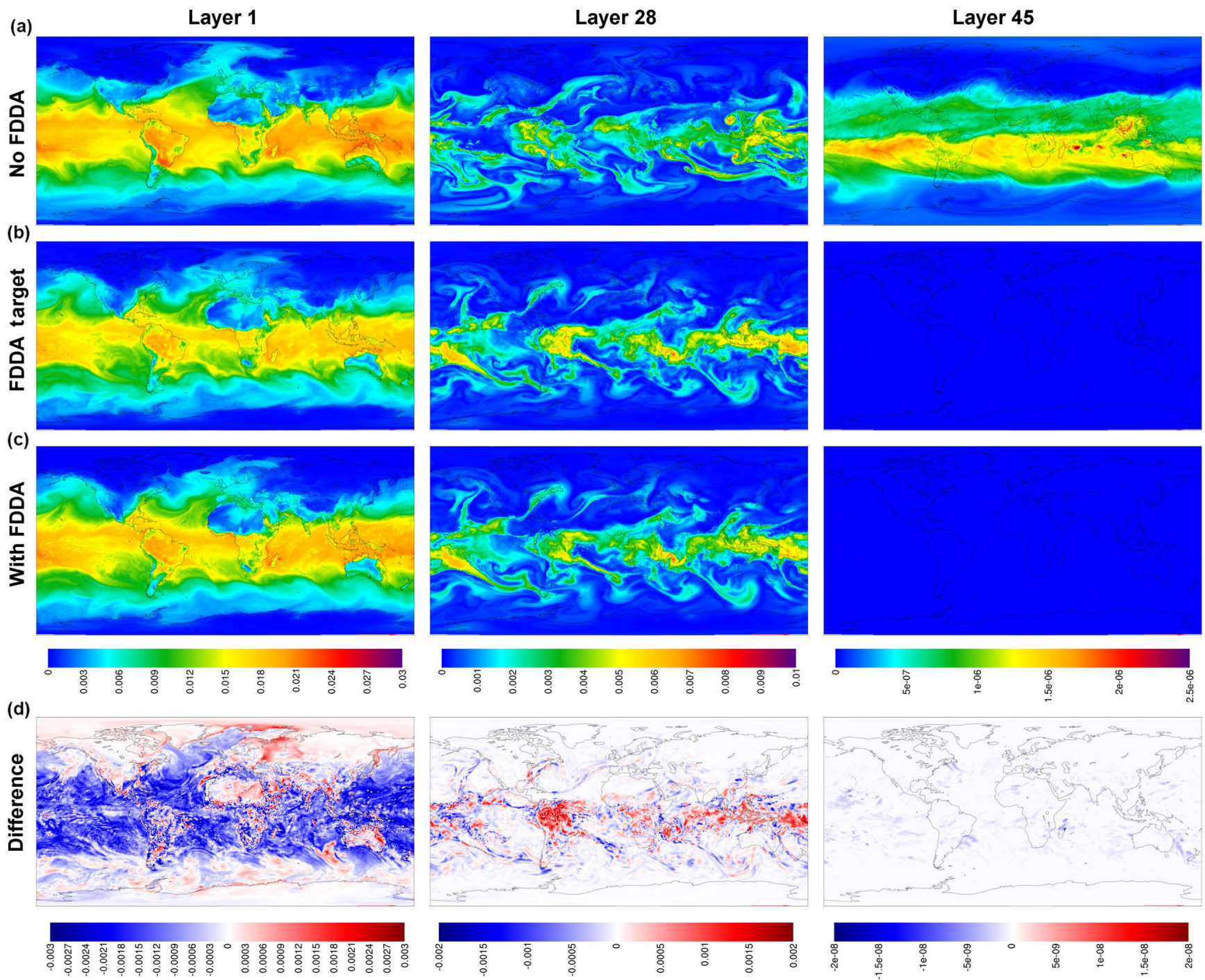

Figure 6. MPAS-A simulation results without FDDA (a), FDDA target fields (b), MPAS-A results with FDDA (c), and FDDA target minus MPAS-A with FDDA (d) for water vapor mixing ratio $\left(\mathrm{kg} \mathrm{kg}^{-1}\right)$ in layers 1, 28, and 45, for 00:00 UTC on 31 January 2013,30 days into the simulation.

surface over the highest resolved terrain. The vertical span of layer 28 varies from 5002-5551 to 9449-9784 m a.m.s.l. depending on the resolved terrain height which varies from -82 to $5425 \mathrm{~m}$. So layer 28 represents a $330-550 \mathrm{~m}$ thick layer somewhere in the middle troposphere. The span of layer 45 varies from 20 622-22 024 to 20 682-22 048 m a.m.s.l. Layer 45 varies only slightly due to the MPAS-A hybrid vertical coordinate system having shifted almost completely to a height coordinate at that altitude in the lower stratosphere.

By 10 days into the simulation, the simulation without FDDA already shows significant potential temperature differences from the FDDA target fields in all three layers shown in Fig. 2. These differences are especially noticeable in layer 45 where an apparent stratospheric warming event is stronger in the "no FDDA" simulation and is longitudinally displaced about $120^{\circ}$ from the location in the reanalysisbased target field. The unconstrained simulation also shows a high-latitude cold pool that is not in the target field and much colder stratospheric temperatures over the tropics. There are also some interesting differences in layer 28 around the high terrain of the Himalayas where the "no FDDA" simulation resulted in much warmer temperatures than the target values. The simulation with FDDA matches the target fields for $\Theta$ almost perfectly for layers 28 and 45 . Near the surface, maps for layer 1 show difference from the $\Theta$ target field in both MPAS-A simulations, mostly in Arctic regions where simulated temperatures are generally colder. But the simulation with FDDA shows surface temperatures closer to the target values even though FDDA was not applied in the PBL. 

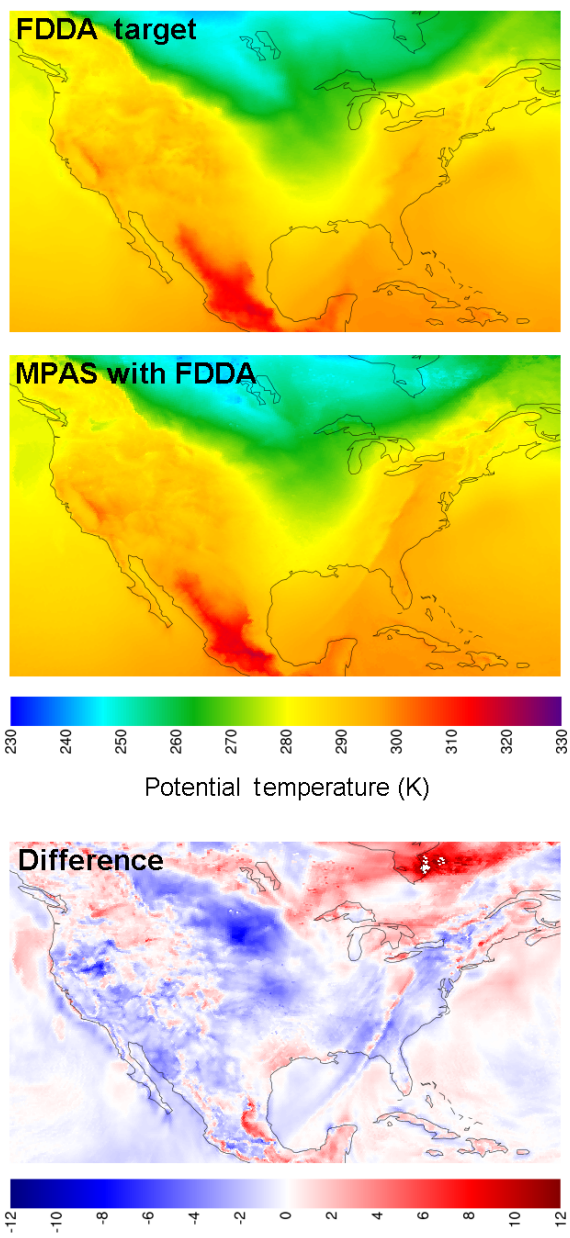
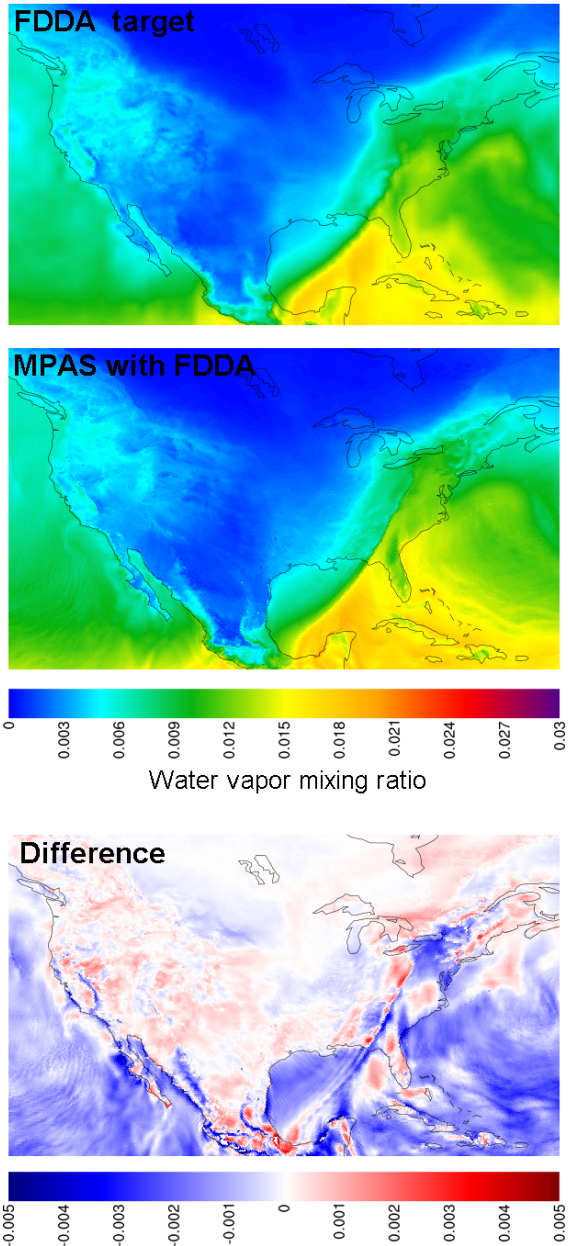

Figure 7. Simulation results from MPAS-A using FDDA and FDDA target fields for potential temperature (K) and water vapor mixing ratio $\left(\mathrm{kg} \mathrm{kg}^{-1}\right)$ in layer 1 at 00:00 UTC on 31 January 2013 focused on the contiguous United States. The difference fields indicate FDDA target minus MPAS-A with FDDA to match the polarity of nudging.

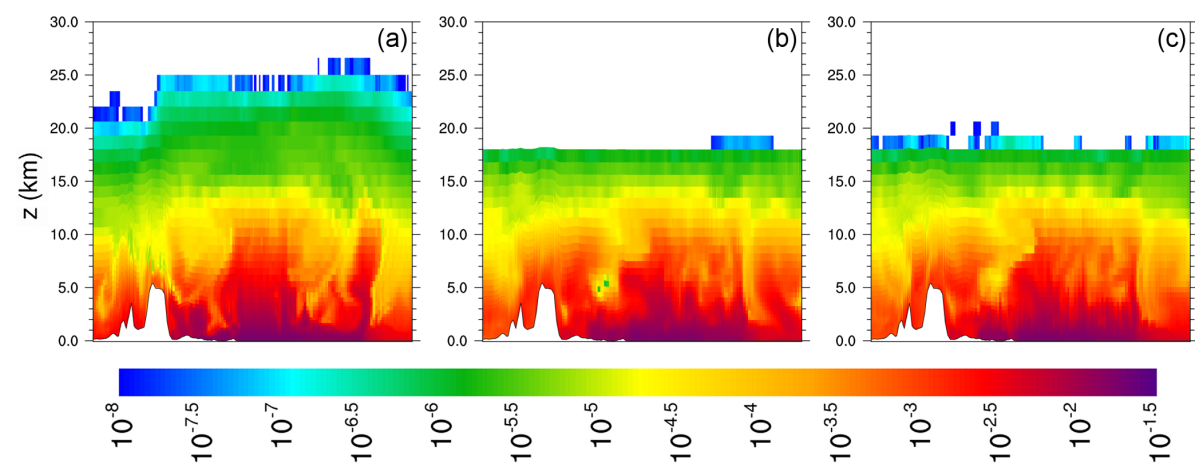

Figure 8. Cross-sectional plots of water vapor mixing ratio $\left(\mathrm{kg} \mathrm{kg}^{-1}\right)$ along longitude $80^{\circ} \mathrm{E}$ from $55^{\circ} \mathrm{N}$ to $55^{\circ} \mathrm{S}$ for $00: 00 \mathrm{UTC}$ on 31 January 2013 (a) from MPAS-A without FDDA, (b) FDDA target field, and (c) MPAS-A using FDDA at 1/10 the strength compared to the other nudged variables. 

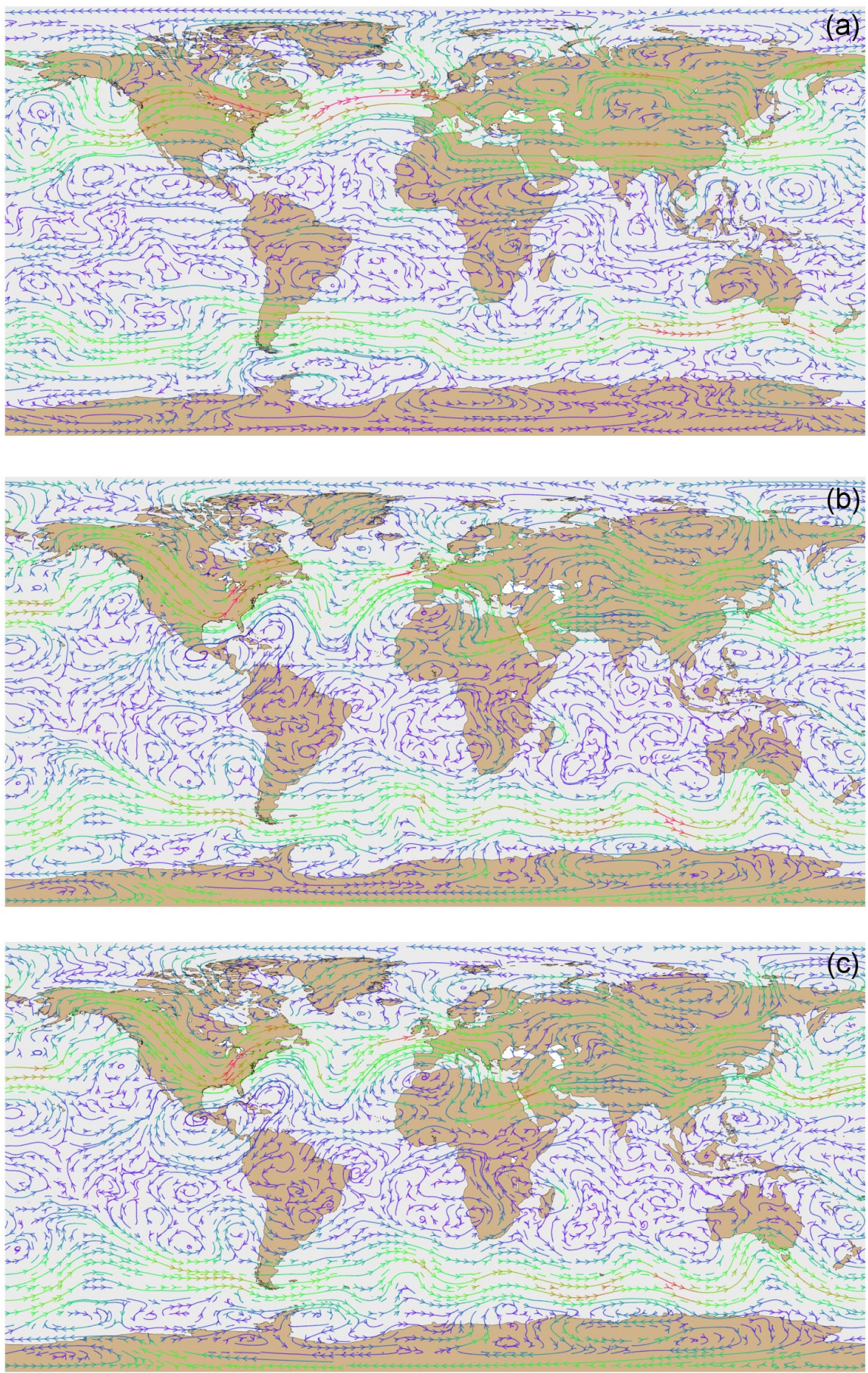

$\begin{array}{lllllllllllll}0 & 5 & 10 & 15 & 20 & 25 & 30 & 35 & 40 & 45 & 50 & 55 & 60\end{array}$

Figure 9. Global streamline analyses for layer $28(\sim 500-300 \mathrm{hPa})$ at 00:00 UTC on 31 January 2013 (a) from MPAS-A without FDDA, (b) FDDA target field, and (c) MPAS-A using FDDA. Streamline color indicates wind speed ( $\mathrm{m} \mathrm{s}^{-1}$ ). 

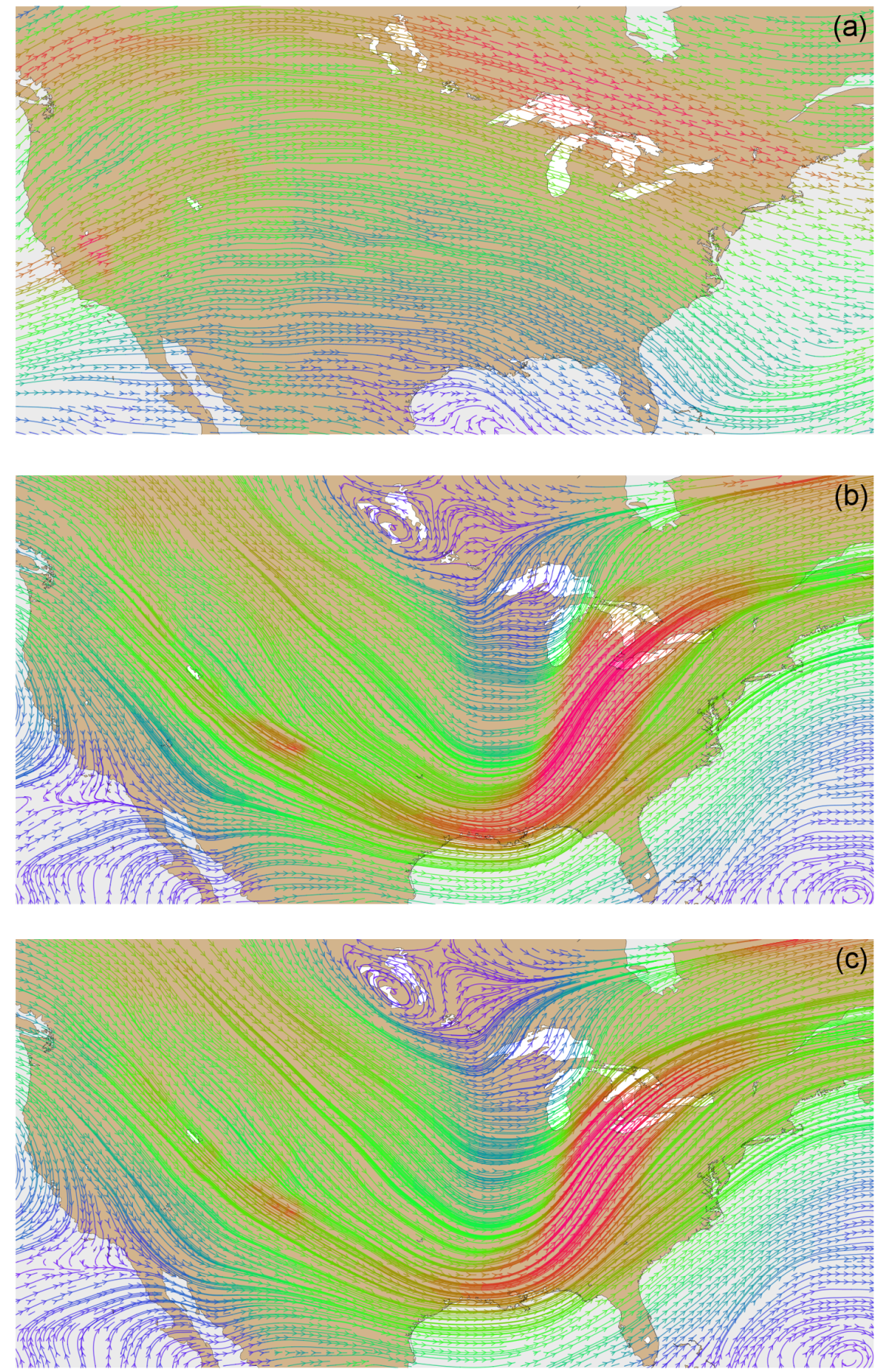

$\begin{array}{lllllllllllll}0 & 5 & 10 & 15 & 20 & 25 & 30 & 35 & 40 & 45 & 50 & 55 & 60\end{array}$

Figure 10. Streamline analyses for layer $28(\sim 500-300 \mathrm{hPa})$ at 00:00 UTC on 31 January 2013 focused on the contiguous United States (a) from MPAS-A without FDDA, (b) FDDA target field, and (c) MPAS-A using FDDA. Streamline color indicates wind speed (m $\mathrm{s}^{-1}$ ). 

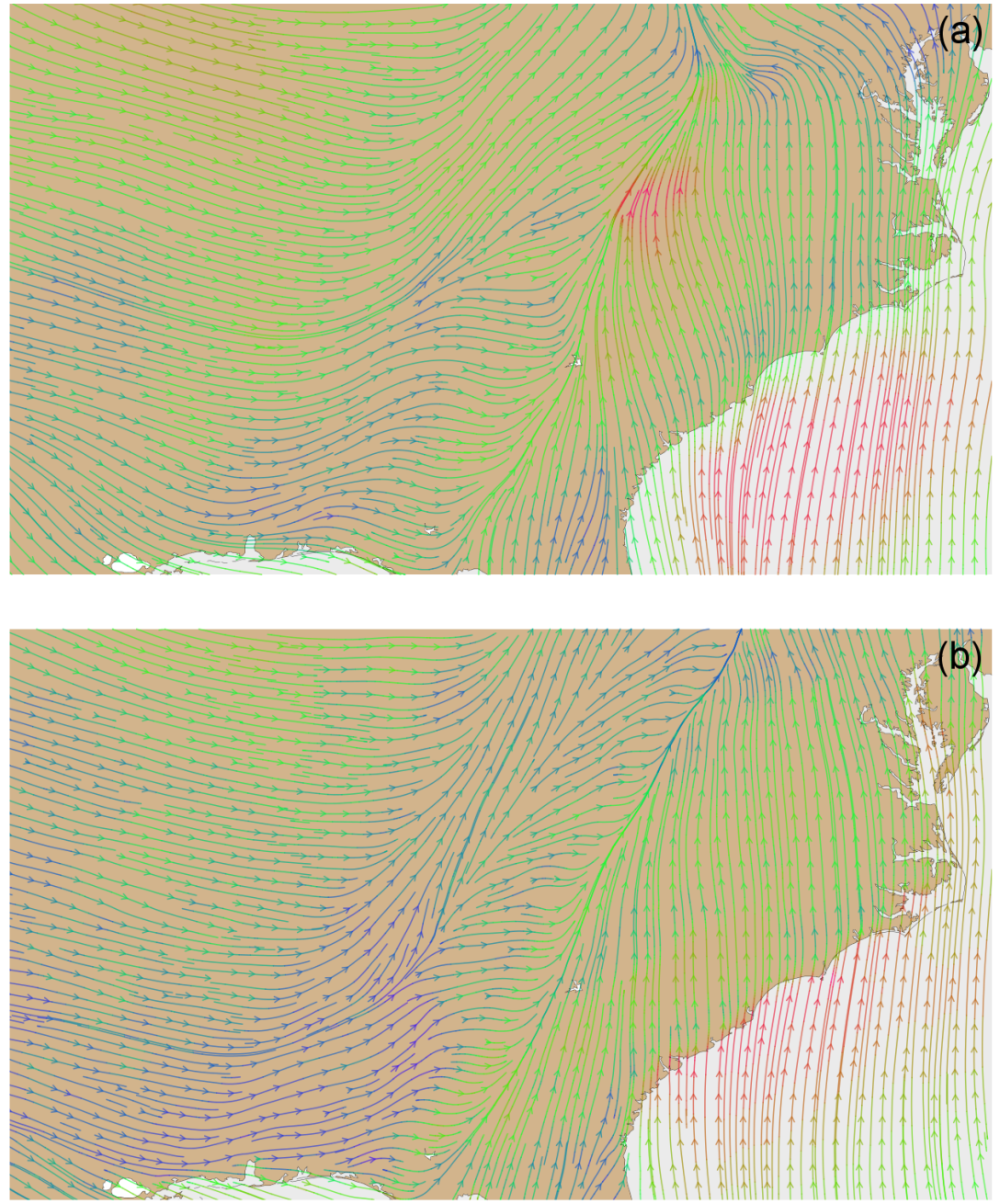

$\begin{array}{lllllllllllllllllll}1 & 2 & 3 & 4 & 5 & 6 & 7 & 8 & 9 & 10 & 11 & 12 & 13 & 14 & 15 & 16 & 17 & 18 & 19\end{array}$

Figure 11. Streamline analysis for layer 1 (surface) at 00:00 UTC on 31 January 2013 focused on the southeastern United States (a) from MPAS-A using FDDA and (b) FDDA target field. Streamline color indicates wind speed $\left(\mathrm{m} \mathrm{s}^{-1}\right)$.

To demonstrate that FDDA continues to constrain MPASA simulations through longer time periods, Fig. 3 shows the same information as Fig. 2, but this time the $\Theta$ fields are for 00:00 UTC, 31 January 2013, 30 days into the simulation. The deviation of the "no FDDA" simulation from the target fields is larger than at day 10, but the results from the simulation with FDDA continue to follow the target fields closely for layers 28 and 45 . However, layer 1 continues to be too cold across the Arctic with FDDA applied above the PBL. The simulation without FDDA is too cold in some parts of the Arctic and too warm in others, and significant deviations from the target field are apparent in many locations around the globe. A quick investigation of observed surface temperatures at Utqiagvik (formerly Barrow), Alaska, found that the simulated surface temperatures are about $10 \mathrm{~K}$ too cold at that location in the FDDA simulation. This points to the fact that FDDA applied only above the PBL can keep simulated temperatures at the surface from being too high due to the effect of convective mixing, but it cannot prevent them from being too cold. Work is ongoing to remedy both warm and cold biases in surface temperature through the use of other land surface and PBL models which nudge soil temperature and moisture towards known conditions.

To investigate temporal variability of the nudging effects on $\Theta$, the simulated and target values for January 2013 were plotted for layer 28 at Research Triangle Park, $\mathrm{NC}\left(35.93^{\circ} \mathrm{N}\right.$, $78.96^{\circ} \mathrm{W}$ ), along with the value of the nudging term. The results in Fig. 4 show that the simulated values tracked the FDDA target values quite closely but do deviate at times. Simultaneously, the nudging term increases in magnitude to 

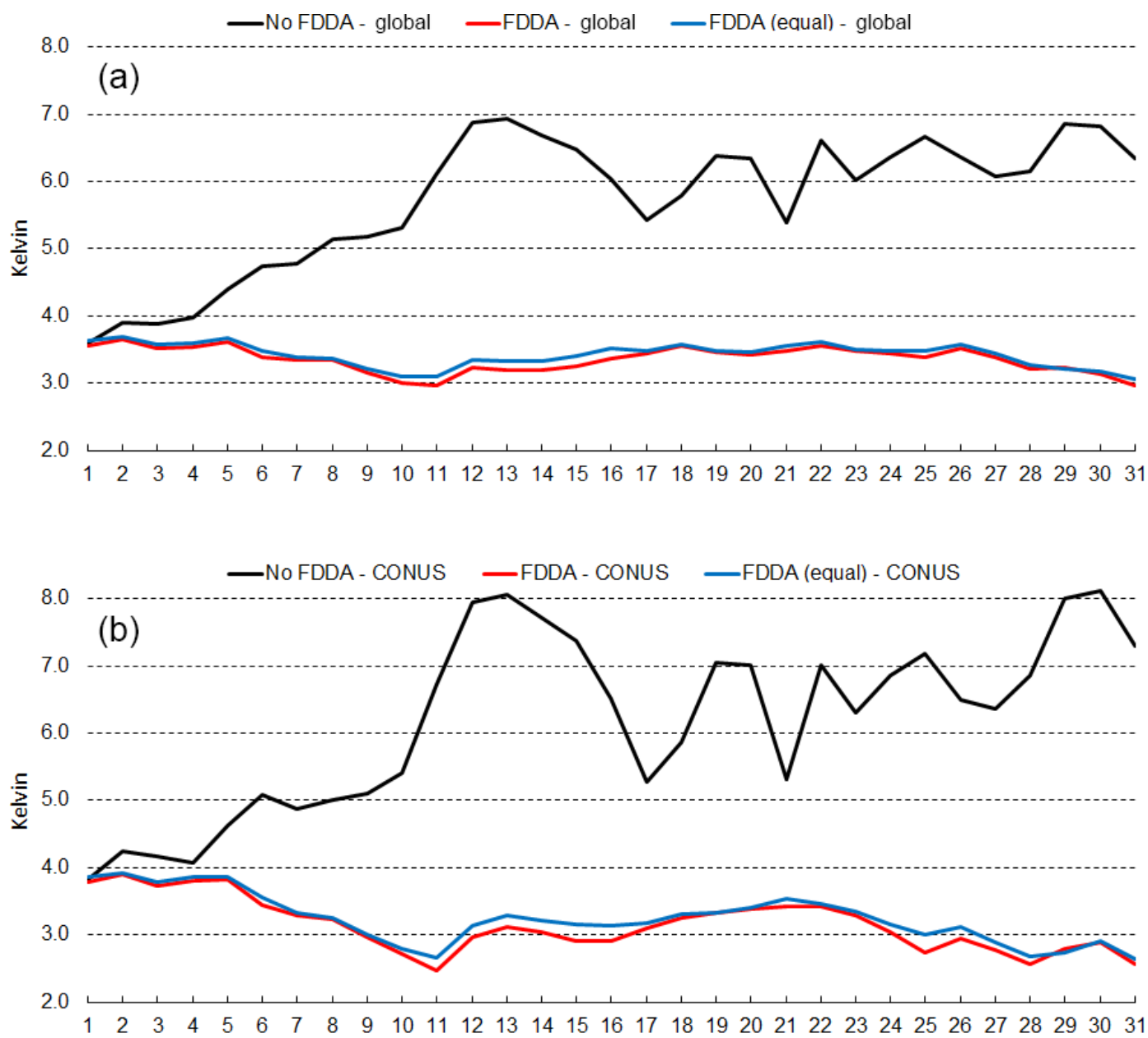

Days of the simulation

Figure 12. January 2013 time series plots of $2 \mathrm{~m}$ temperature root mean squared error (RMSE) for MPAS-A without FDDA (black line), MPAS-A with FDDA applied using weaker $q_{\mathrm{v}}$ nudging (red line), and MPAS-A with FDDA applied at equal strength for all variables (blue line). Panel (a) shows results for the entire global domain, while (b) shows results for the CONUS subdomain.

counteract these deviations. A significant perturbation is evident at around 00:00 UTC on 18 January. To investigate this occurrence and to illustrate the spatial variability of the nudging, spatial plots of the $\Theta$ nudging term were made for layer 28 at 00:00 UTC on 18 January, one with a focus on North America and the second showing the entire global domain. Figure 5 shows the spatial extent of the perturbation and the spatial patterns of positive and negative forcing at that time. These patterns match the spatial scale of meteorological features where model error might grow over time were it not for the corrective effects of analysis nudging.

The array of maps in Fig. 6 shows water vapor mixing ratio at 00:00 UTC, 31 January 2013, in the same arrangement as for potential temperature in Fig. 3. Even with weak $q_{\mathrm{v}}$ nudging, the simulation with FDDA matches the target fields well for all three layers. Without FDDA, the simulated pattern of water vapor deviates significantly from the target in all layers. In layer 45, the "no FDDA" case shows higher $q_{\mathrm{v}}$ values all across the tropics than exist in the target field or in the simulation with FDDA where water vapor is practically absent. These results suggest that even weak nudging of water vapor can mitigate what appears to be artificial vertical diffusion of tropospheric water vapor into the stratosphere.

Figure 7 shows layer 1 fields at 00:00 UTC, 31 January 2013, for potential temperature and water vapor mixing ratio, but this time focused on the contiguous United States (CONUS). At this point in time, a strong cold front stretching from western Pennsylvania, down the Appalachian Mountains, and into the Gulf of Mexico was advancing from the west. It is important to note once again that analysis nudging was only applied above the PBL. Nonetheless, not only does the simulation with FDDA place the front in the correct location, but the simulated front shows sharper detail for $\Theta$ and $q_{\mathrm{v}}$ than in the target fields. This is especially true for $q_{\mathrm{v}}$ 


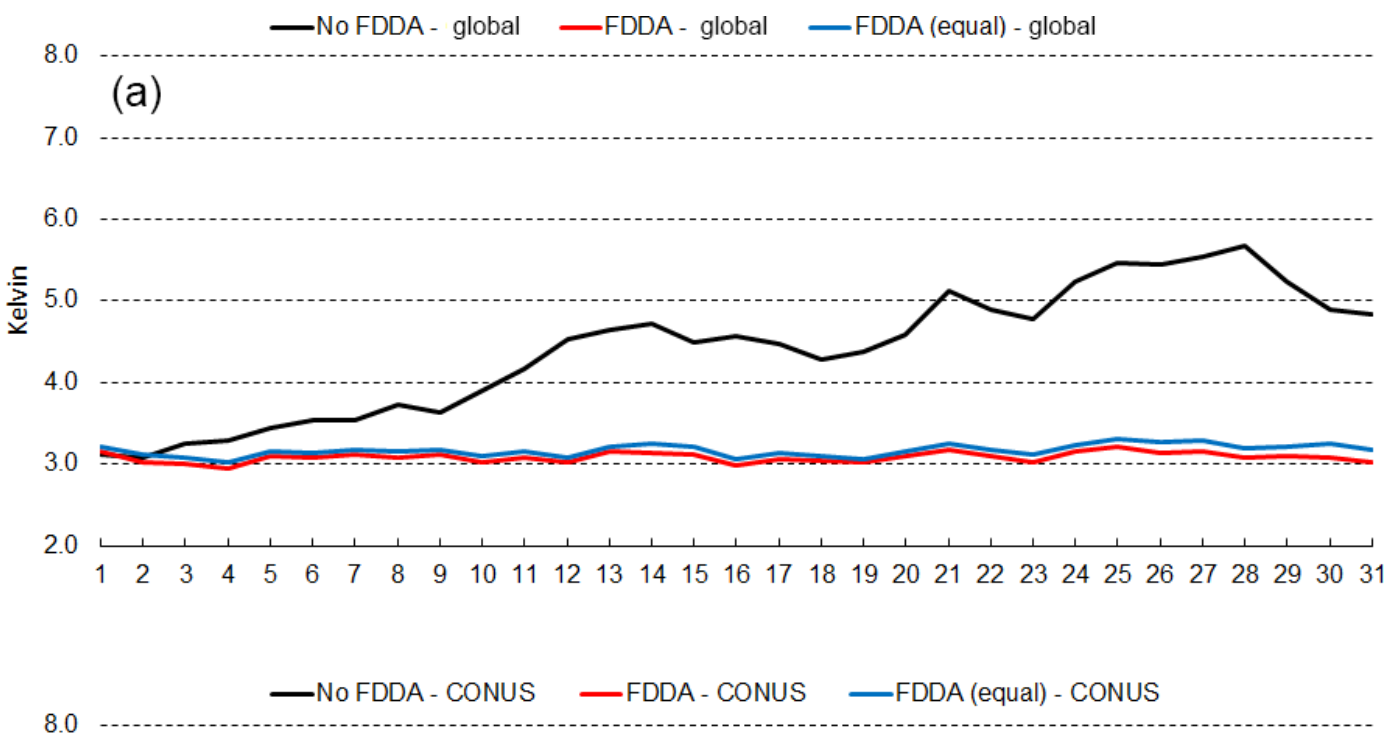

(b)

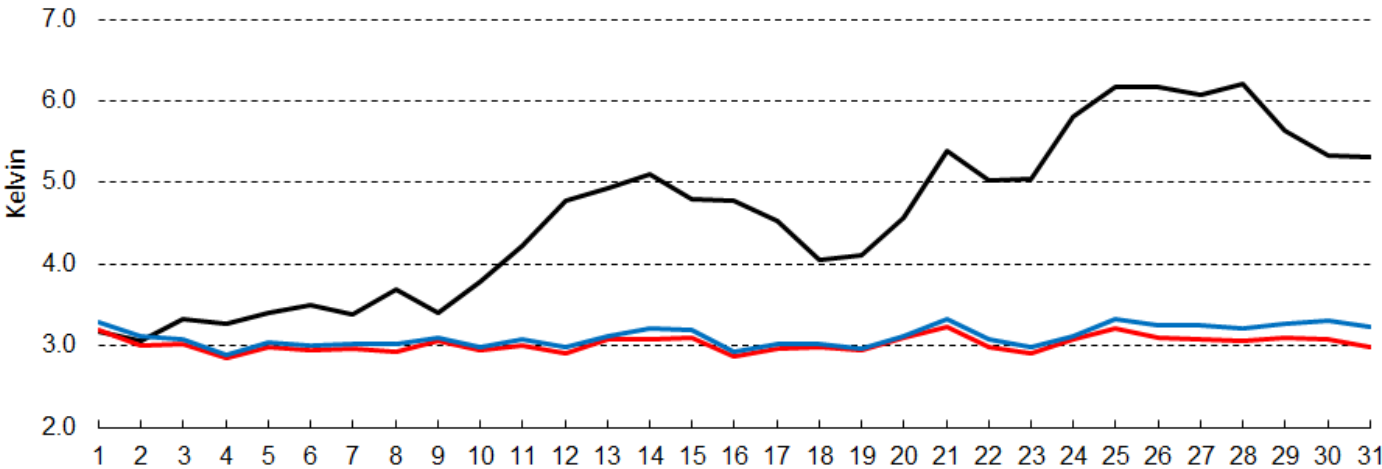

Days of the simulation

Figure 13. July 2013 time series plots of $2 \mathrm{~m}$ temperature RMSE for MPAS-A without FDDA (black line), MPAS-A with FDDA applied using weaker $q_{\mathrm{v}}$ nudging (red line), and MPAS-A with FDDA applied at equal strength for all variables (blue line). Panel (a) shows results for the entire global domain, while (b) shows results for the CONUS subdomain.

where it appears that weaker nudging above the PBL allows simulated details at the surface to be better conserved. Finer detail is evident, not only along the cold front but also in other locations where it appears variations in terrain and land cover type may be important. It stands to reason that if nudging had been applied within the PBL, these simulated fine details at the surface would have been blurred somewhat by blending with the less resolved target fields. Of course, finer detail does not in itself indicate better accuracy. To address that issue, simulation results were also compared to observational data as described later in Sect. 3.2.

Vertical cross-section plots of water vapor mixing ratio show that FDDA can constrain undesirable model behavior even when the nudging strength is quite weak. Figure 8 shows vertical cross sections along longitude $80^{\circ} \mathrm{E}$ from $55^{\circ} \mathrm{N}$ to $55^{\circ} \mathrm{S}$ for 00:00 UTC, 31 January 2013 (day 30). This particular location was chosen to investigate the ef- fect of the Himalayas on MPAS-A simulation results. The height of the Himalayas $(\sim 5 \mathrm{~km})$ as resolved by the $92 \mathrm{~km}$ mesh size is shown by the white area at the bottom of each plot. Figure 8a shows the standard MPAS simulation result, Fig. 8b shows the FDDA target field, and Fig. 8c shows the results from MPAS-A with FDDA using moisture nudging at $1 / 10$ the strength used for the other variables. As previously seen in Fig. 6, the unconstrained simulation shows signs of upward transport and/or diffusion of water vapor into the lower stratosphere with water vapor mixing ratios over 2 orders of magnitude higher than the target values. The simulation with FDDA almost completely eliminates this deviation from the target, even with the weak nudging strength.

Wind velocities and flow patterns from MPAS-A simulations and FDDA target fields were investigated with streamline plots. Figure 9 shows global streamline analyses for layer $28(\sim 500-300 \mathrm{hPa})$, again for 00:00 UTC, 31 Jan- 


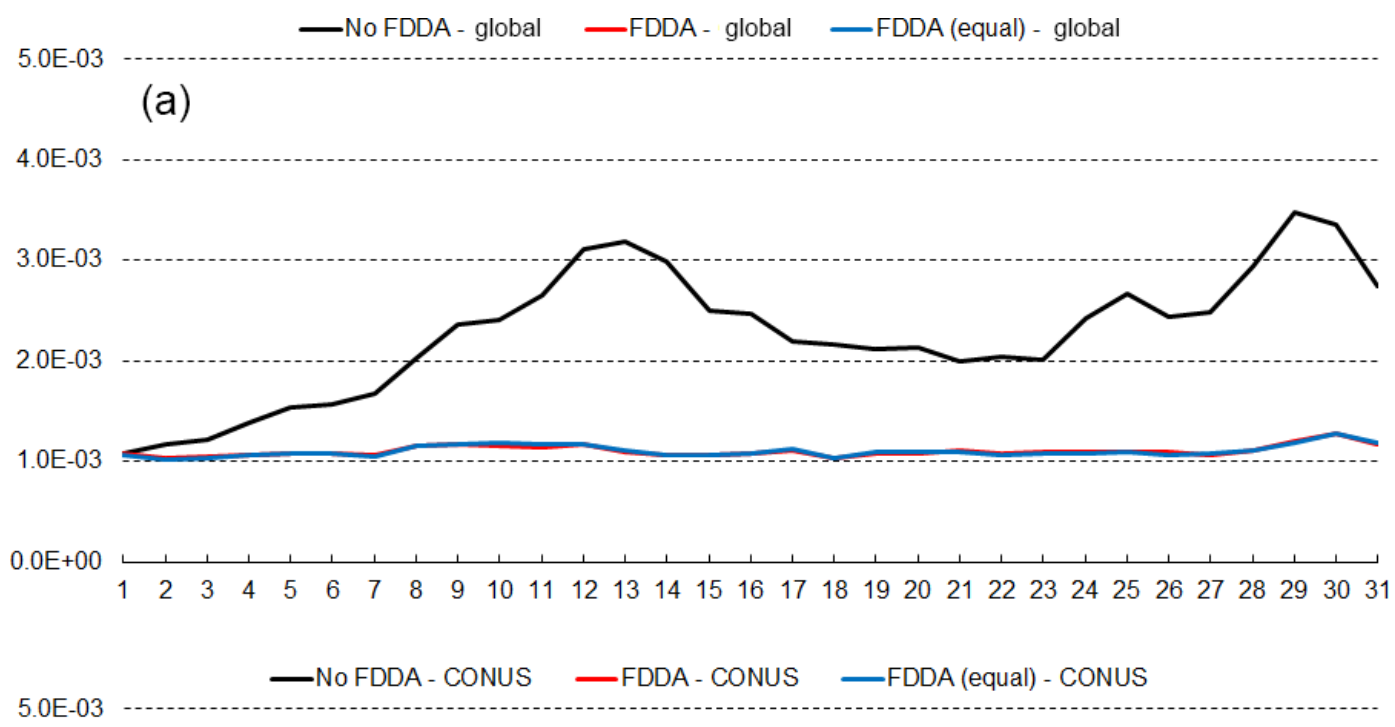

(b)

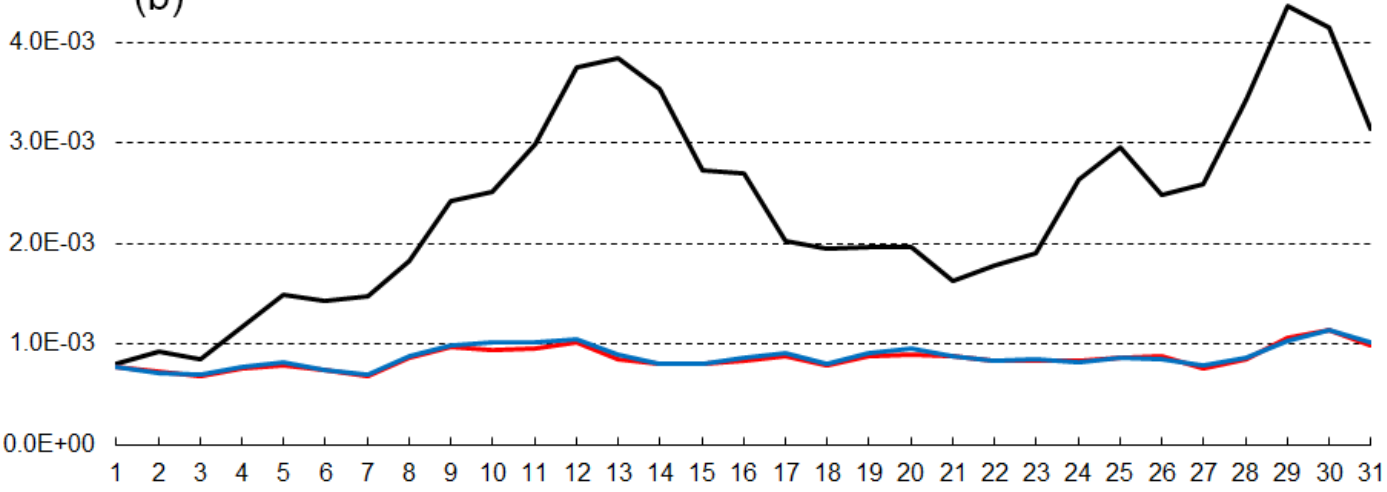

Days of the simulation

Figure 14. January 2013 time series plots of $2 \mathrm{~m}$ water vapor mixing ratio $\left(q_{\mathrm{v}}\right)$ RMSE for MPAS-A without FDDA (black line), MPAS-A with FDDA applied using weaker $q_{\mathrm{v}}$ nudging (red line), and MPAS-A with FDDA applied at equal strength for all variables (blue line). Panel (a) shows results for the entire global domain, while (b) shows results for the CONUS subdomain.

uary 2013. As might be expected from a 30-day forecast, the flow field from the simulation without FDDA (Fig. 9a) differs significantly from the FDDA target flow field (Fig. 9b). However, the simulation with FDDA (Fig. 9c) follows the FDDA target data almost perfectly. To show the ability of FDDA to maintain finer-scale fidelity, similar streamline analyses focused on the CONUS are shown in Fig. 10. Again, the simulation with FDDA is almost identical to the target flow field. Streamline analysis for layer 1 focused on the southeastern US. Figure 11 shows some noticeable differences between the simulation with FDDA and the target field. These differences are not surprising given that no nudging was applied in the PBL. Also, the FDDA target fields above the PBL were derived from $1^{\circ}$ FNL reanalysis data, while the simulation cell size is $\sim 25 \mathrm{~km}$ in this region. Terrain effects on wind flow direction and speed appear to be more significant in the simulation than in the FDDA target field.
Similar comparisons of MPAS-A simulations to FDDA target data were made for the July 2013 test period. All of these comparisons showed essentially the same results as were found for January 2013. While weather systems and patterns were generally more quiescent, at least in the Northern Hemisphere, simulations unconstrained by FDDA still deviated significantly from target fields after a few days, while those constrained by FDDA maintained their fidelity relative to the target data.

\subsection{Comparisons to observational data}

MPAS-A simulation results were compared to observations of $2 \mathrm{~m}$ temperature, $2 \mathrm{~m}$ humidity, and $10 \mathrm{~m}$ wind speed. To assure data quality, only aviation routine weather reports (METAR) and surface airways observation (SAO) reports from the MADIS repository were used. This comparison was made using the Atmospheric Model Evaluation Tool 


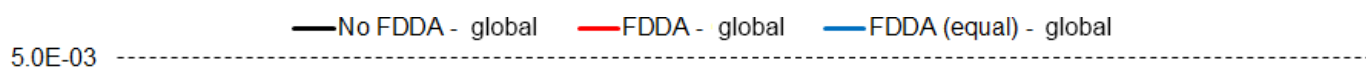

(a)

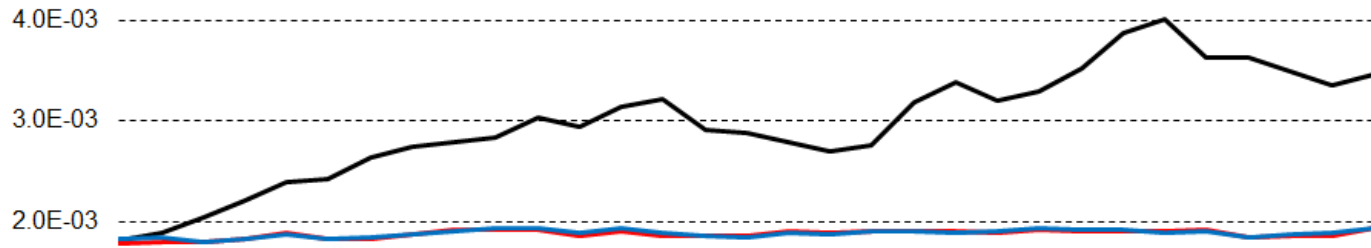

$1.0 \mathrm{E}-03$

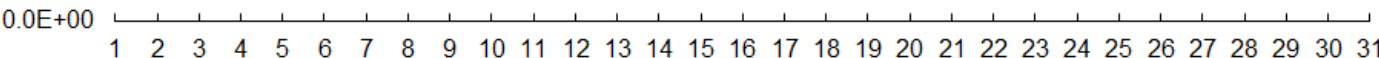

—No FDDA - CONUS -FDDA - CONUS —FDDA (equal) - CONUS

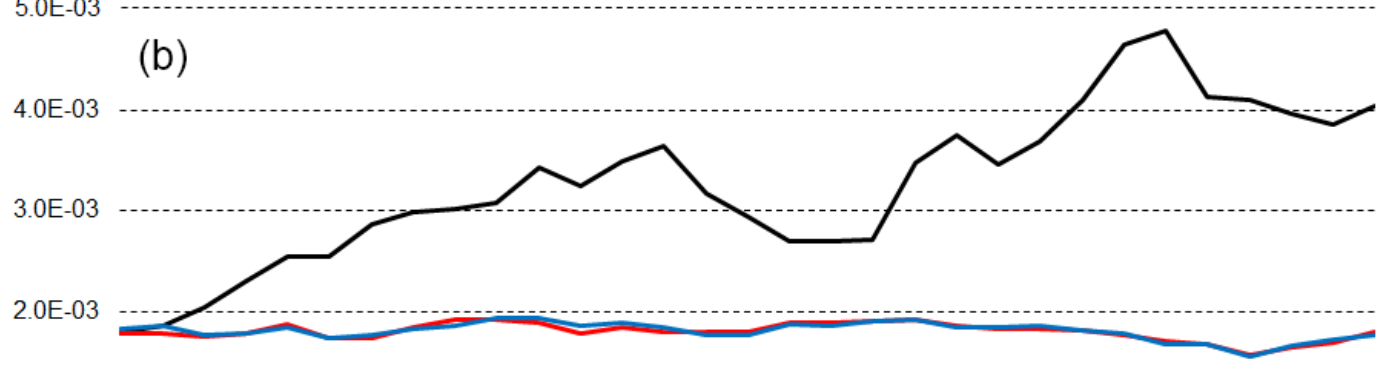

1.0E-03

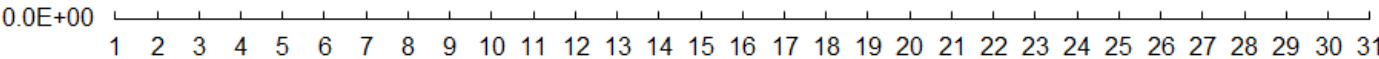

Days of the simulation

Figure 15. July 2013 time series plots of $2 \mathrm{~m}$ water vapor mixing ratio $\left(q_{\mathrm{v}}\right)$ RMSE for MPAS-A without FDDA (black line), MPAS-A with FDDA applied using weaker $q_{\mathrm{v}}$ nudging (red line), and MPAS-A with FDDA applied at equal strength for all variables (blue line). Panel (a) shows results for the entire global domain, while (b) shows results for the CONUS subdomain.

(AMET) described in Appel et al. (2011). AMET was configured to calculate daily evaluation statistics for the entire global domain and for a subdomain confined within 25 to $50^{\circ} \mathrm{N}$ latitude and 67 to $125^{\circ} \mathrm{W}$ longitude, basically covering the CONUS where the horizontal mesh size was $25 \mathrm{~km}$. Daily statistics were calculated for both the January and July 2013 test periods.

Figure 12 shows the time series of $2 \mathrm{~m}$ temperature root mean squared error (RMSE) for January 2013. The top graph shows results for the entire global domain, while the bottom graph shows results for the CONUS subdomain. Three MPAS-A simulations were analyzed, the standard model denoted as no FDDA, FDDA applied using relatively weak $q_{\mathrm{v}}$ nudging denoted as $F D D A$, and FDDA applied using equal nudging strength for all variables denoted as FDDA (equal). The no FDDA cases show error increasing right from the start, both globally and over the CONUS. For the global do- main, the FDDA and FDDA (equal) cases both show RMSE actually decreasing somewhat over the first 10 days but generally holding steady throughout the month. Globally, model performance with weak $q_{\mathrm{v}}$ nudging is slightly better than with equal nudging strength for $\Theta, q_{\mathrm{v}}$, and $U$. In the CONUS analysis, $2 \mathrm{~m}$ temperature RMSE for the FDDA case decreases more significantly over the first 10 days than in the global analysis and remains below the starting values throughout the remainder of the month. Once again, relatively weak $q_{\mathrm{v}}$ nudging improves model error statistics to some degree.

Figure 13 shows the same information as Fig. 12, except this time for July 2013. RMSE values are generally lower than those for January 2013, but the same relationships hold between the no FDDA case and the other two cases. Slight reductions in $2 \mathrm{~m}$ temperature RMSE result from the use of weaker $q_{\mathrm{v}}$ nudging. Another interesting aspect of the results 

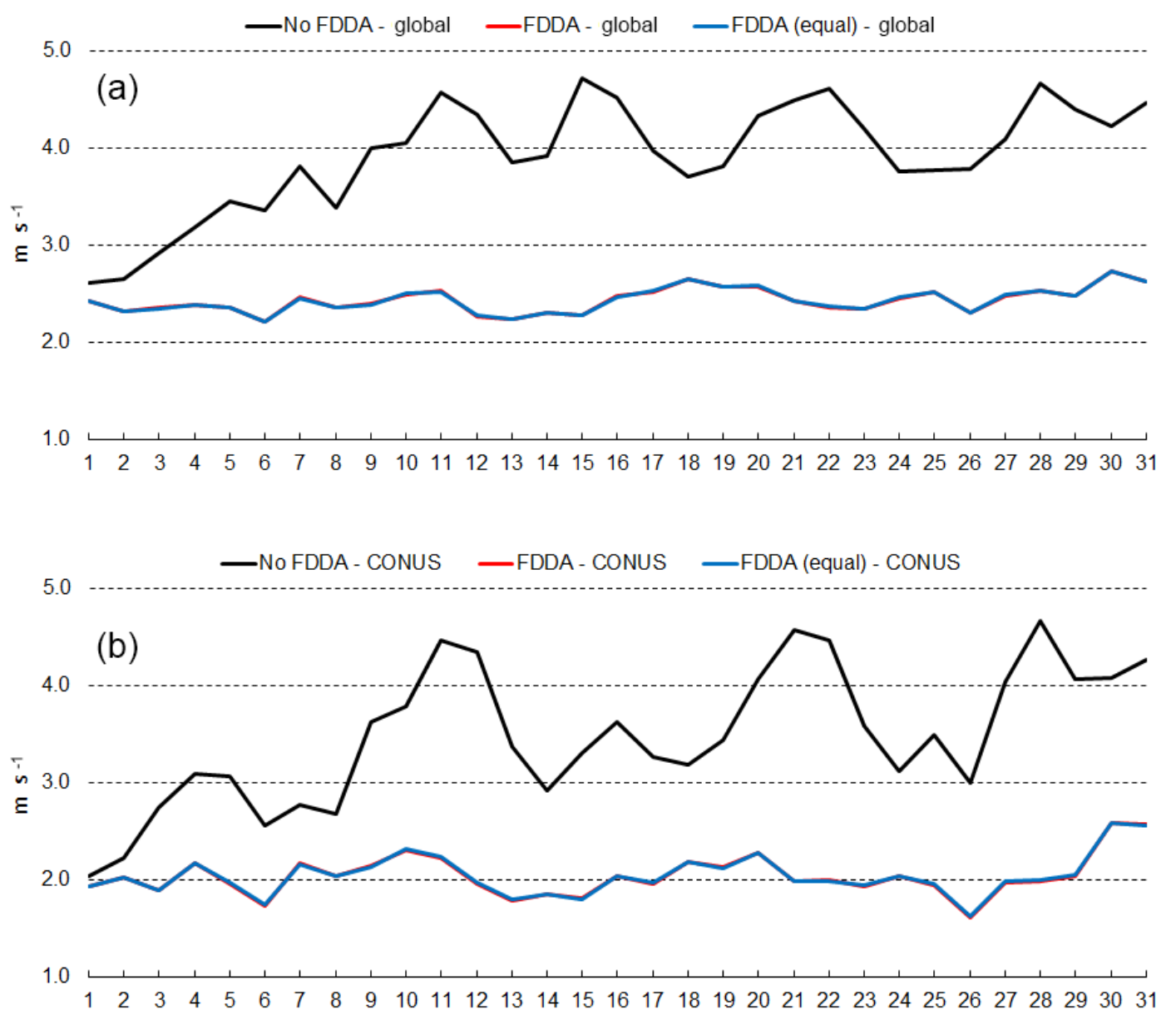

Days of the simulation

Figure 16. January 2013 time series plots of $10 \mathrm{~m}$ wind speed RMSE for MPAS-A without FDDA (black line), MPAS-A with FDDA applied using weaker $q_{\mathrm{v}}$ nudging (red line), and MPAS-A with FDDA applied at equal strength for all variables (blue line). Panel (a) shows results for the entire global domain, while (b) shows results for the CONUS subdomain.

in Figs. 12 and 13 is the temporal correlation of RMSE for the global domain and the CONUS subdomain. This is probably due to the high concentration of METAR observation sites over the CONUS. The same behavior is found to varying degrees in the results shown below for humidity and wind speed.

Figures 14 and 15 show RMSE for $2 \mathrm{~m}$ water vapor mixing ratio $\left(q_{\mathrm{V}}\right)$ during January and July 2013 , respectively. These figures show RMSE values for July 2013 are larger than those for January 2013. This is largely due to the fact that MADIS observations are more concentrated in the Northern Hemisphere. In fact, they are most concentrated in North America. Thus, in the Northern Hemisphere warm season when humidity levels are highest, model errors are also highest. But these figures show for humidity much the same effect of FDDA as was shown for temperature. Without FDDA, model error immediately increases at the start of the simulation and continues to increase for 10 or more days until errors in the unconstrained simulation approach the levels of variation in the actual meteorological fields. From that time on, the magnitude of daily RMSE values fluctuates quite randomly. It is interesting to note in both Figs. 14 and 15 that the simulation with weaker $q_{\mathrm{v}}$ nudging often has slightly lower RMSE than the simulation with equal nudging strength. While the difference is quite small, it is counterintuitive nonetheless. Apparently, the $1^{\circ} \times 1^{\circ}$ NCEP FNL data used to create the FDDA targets, with their relatively coarse resolution compared to the $25 \mathrm{~km}$ MPAS-A mesh used over North America, can degrade the simulation in that area where the MADIS observations are most concentrated. Further study is underway to see if target fields derived from newly available $0.25^{\circ} \times 0.25^{\circ}$ NCEP FNL data lead to the same behavior.

Figures 16 and 17 show RMSE for $10 \mathrm{~m}$ wind speed during January and July of 2013, respectively. As with temperature and humidity, model errors for wind speed begin to increase at the start of both simulations without FDDA and continue 


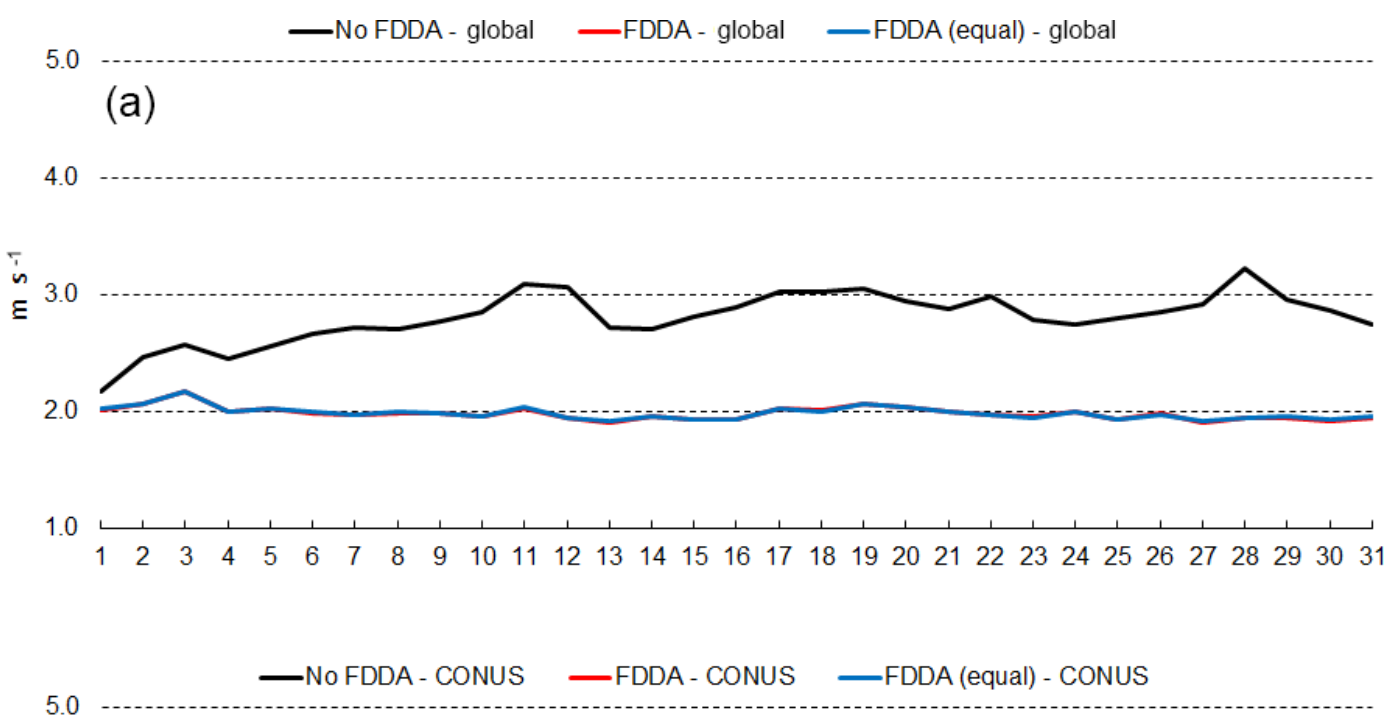

(b)

4.0

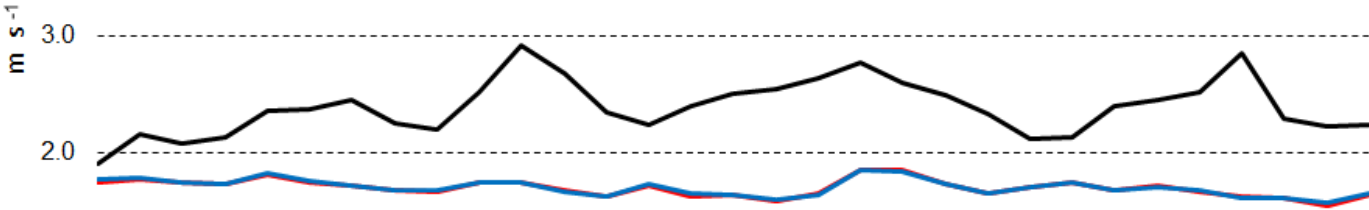

1.0

$\begin{array}{lllllllllllllllllllllllllllllll} & 2 & 3 & 4 & 5 & 6 & 7 & 8 & 9 & 10 & 11 & 12 & 13 & 14 & 15 & 16 & 17 & 18 & 19 & 20 & 21 & 22 & 23 & 24 & 25 & 26 & 27 & 28 & 29 & 30 & 31\end{array}$

Days of the simulation

Figure 17. July 2013 time series plots of $10 \mathrm{~m}$ wind speed RMSE for MPAS-A without FDDA (black line), MPAS-A with FDDA applied using weaker $q_{\mathrm{v}}$ nudging (red line), and MPAS-A with FDDA applied at equal strength for all variables (blue line). Panel (a) shows results for the entire global domain, while (b) shows results for the CONUS subdomain.

to increase for about 10 days. After 10 days, fluctuations in wind speed error in the unconstrained simulations appear to be quite random. The simulations with FDDA, regardless of the nudging strength for $q_{\mathrm{v}}$, continue to have about the same RMSE for wind speed throughout the month, be that January or July of 2013. For wind speed, the strength of $q_{\mathrm{v}}$ nudging appears to have little effect on RMSE. Opposite to what was seen for humidity, the analyzed wind speed errors are largest in the Northern Hemisphere cold season. The concentration of MADIS observations in the Northern Hemisphere is once again likely an important factor in this seasonal difference in wind speed RMSE magnitude.

Even though FDDA nudging was not applied within the PBL for any variable, the results above show model errors near the surface were constrained quite well, except where simulated surface temperatures were too cold. Also, near the surface is where finer horizontal resolution of the model relative to the FDDA target data source has its greatest effect.
Further study is anticipated to better identify optimal FDDA nudging strengths for $\Theta, q_{\mathrm{v}}$, and $U$ in MPAS-A, and to better understand the vertical levels of the atmosphere where nudging should be applied.

\subsection{Mass conservation tests}

In addition to the comparisons described above, the ability of MPAS-A to conserve simulated atmospheric mass was also tested. For each month-long test period, all model simulations reported total atmospheric mass and total water vapor mass at each $150 \mathrm{~s}$ simulation time step. This was accomplished with minor additions to the Fortran code in the time integration module (./src/core_atmosphere/dynamics/mpas_atm_time_ integration.F). The modified module is included in the model code repository (https://doi.org/10.5281/zenodo.1101204).

As shown in Fig. 18, all simulations including those with FDDA conserved total moist air within the global model do- 

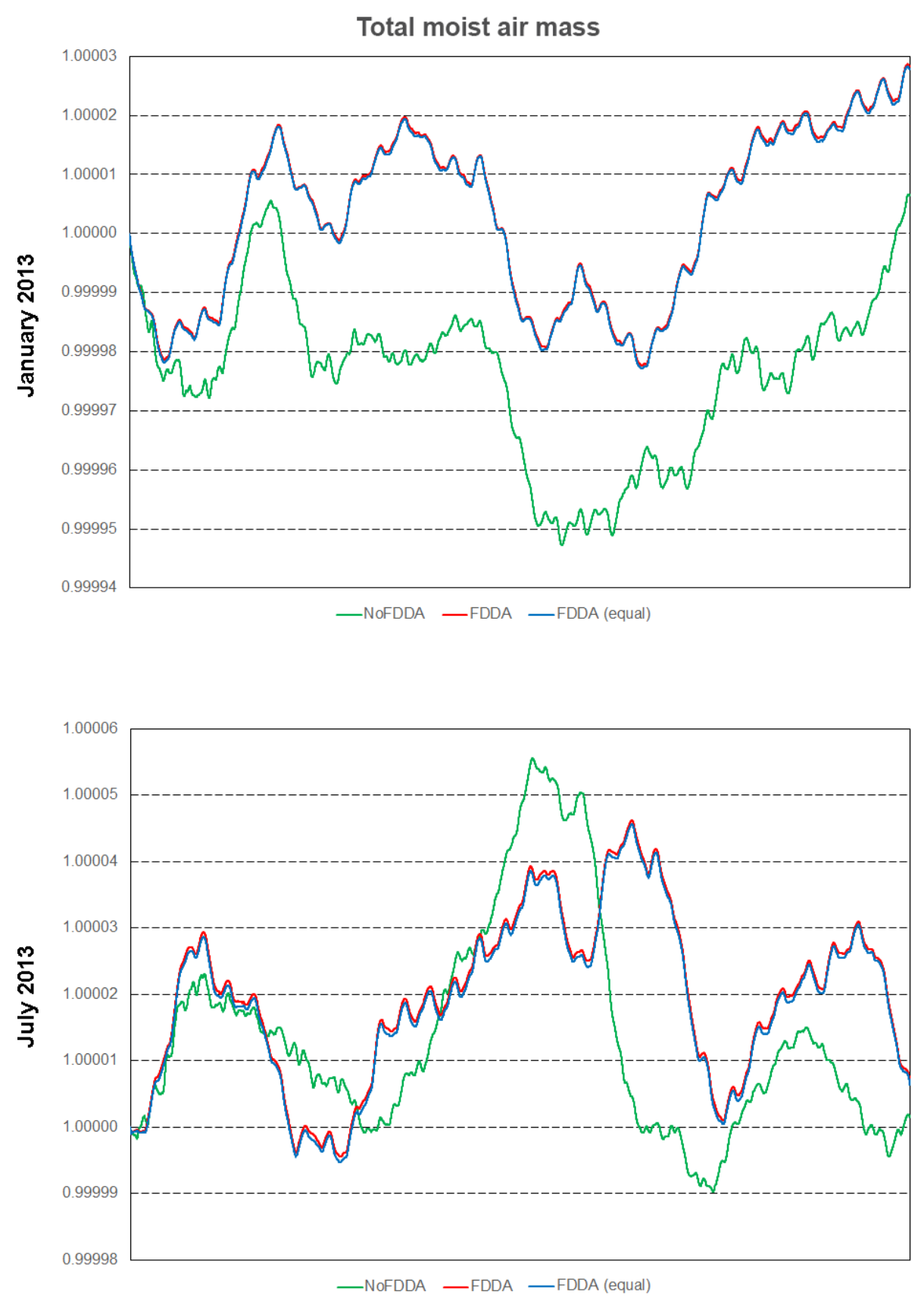

Figure 18. Time series plots of total moist air mass scaled to their initial values for the two test periods. Results are from MPAS-A without FDDA (green line), MPAS-A using weaker $q_{\mathrm{v}}$ nudging (red line), and MPAS-A using equal nudging for all variables (blue line).

main to within 5 parts in 100000 of their starting values. Total water vapor mass (Fig. 19) varied more significantly in time in each simulation, and this is to be expected due to evaporation and precipitation processes. There is a diurnal signal evident in the water vapor mass total from all simulations, most likely due to longitudinal variations in evaporation and precipitation potential under solar radiation caused by the geographic distribution of continents and oceans. For January 2013, the no FDDA simulation lost over $5 \%$ of its initial quantity of water vapor. This could be indicative of too much simulated precipitation, too little simulated evaporation, or both. Also, the model initialization based on the NCEP FNL analysis could be too moist. The simulations with FDDA all tended to maintain more total water vapor relative to the standard model. In general, the unconstrained simulations tended to lose water vapor at the start of the simulation and come to an equilibrium point significantly lower than the simulations with FDDA. The FDDA (equal) simula- 

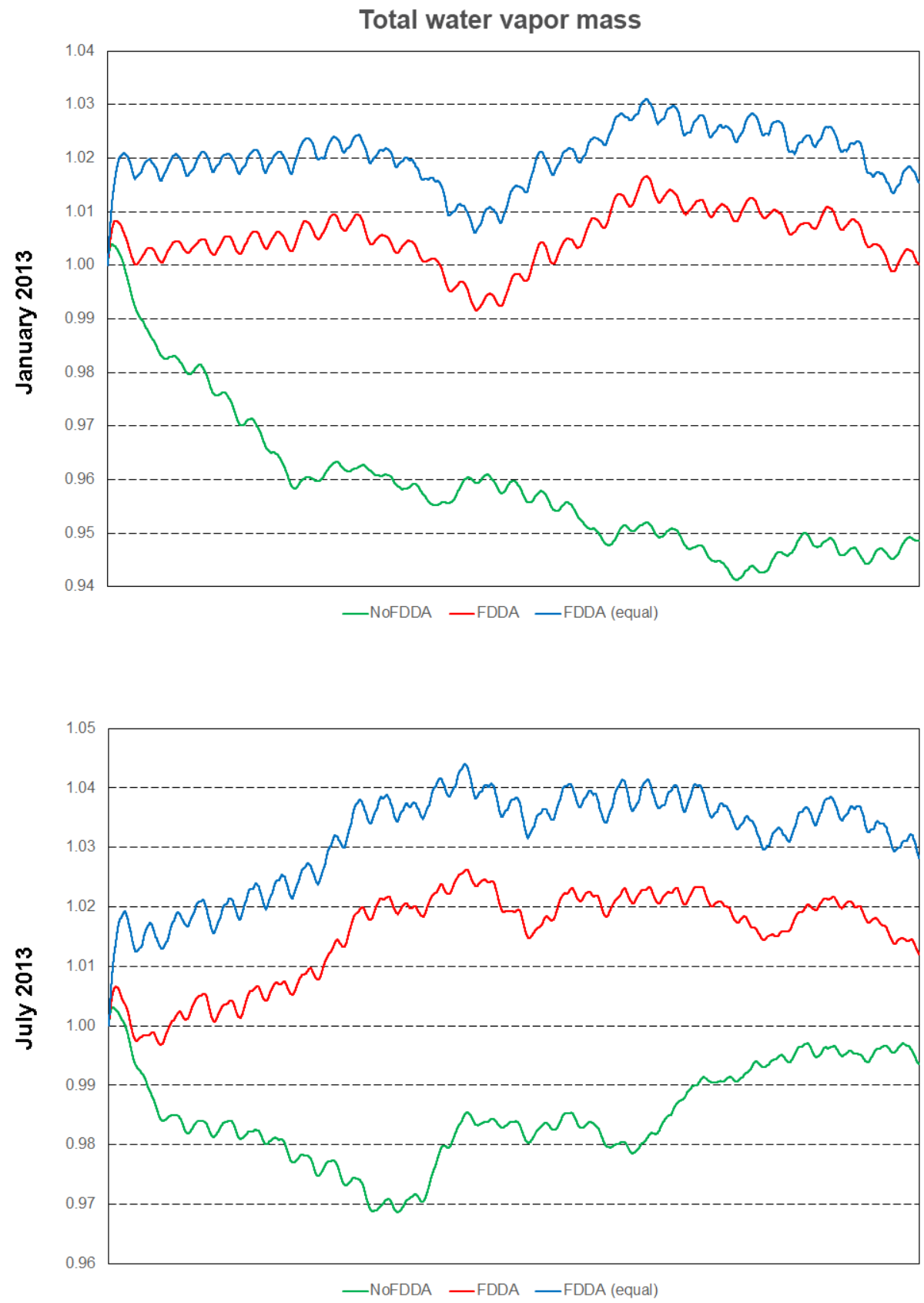

Figure 19. Time series plots of total water vapor mass scaled to their initial values for the two test periods. Results are from MPAS-A without FDDA (green line), MPAS-A using weaker $q_{\mathrm{v}}$ nudging (red line), and MPAS-A using equal nudging for all variables (blue line).

tions tended to quickly establish and then maintain the most total water vapor. Obviously, the FNL analysis indicated a moister atmosphere than the unconstrained MPAS-A simulations could maintain.

It is interesting to note that the FDDA and FDDA (equal) cases had almost identical trends in total moist air mass, with any differences in total water vapor almost perfectly canceled out by differences in dry air (Fig. 20). Also, the January 2013 no FDDA simulation gained total dry air mass to about 13 parts in 100000 of the initial value. This is the same simulation that lost a significant fraction of its initialized water vapor, once again showing an opposite conservation response between dry air and water vapor.

Overall, the results in Figs. 18-20 demonstrate that the addition of FDDA does not degrade mass conservation relative to the standard MPAS-A. Conservation of dry air mass is most important if MPAS-A is to be used as the meteorological driver for air quality modeling. These results show that 

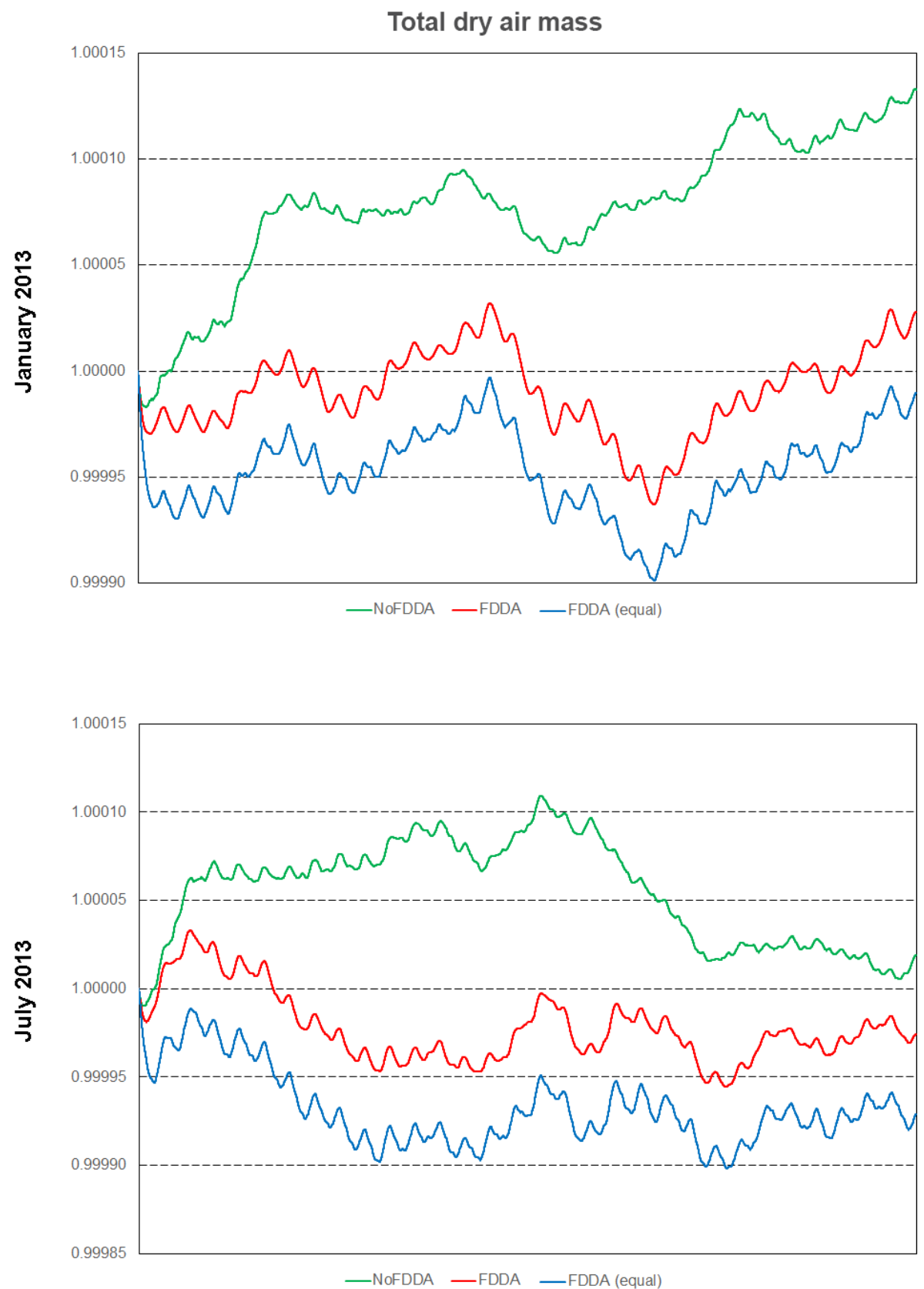

Figure 20. Time series plots of total dry air mass scaled to their initial values for the two test periods. Results are from MPAS-A without FDDA (green line), MPAS-A using weaker $q_{\mathrm{v}}$ nudging (red line), and MPAS-A using equal nudging for all variables (blue line).

using FDDA could actually offer some improvement in that regard.

\section{Summary and conclusions}

The U.S. EPA is working to make MPAS-A suitable for use as the meteorological component of an integrated meteorology and air quality modeling system for global-to-fine-scale applications. The ability to constrain simulated meteorology to resemble historical reanalysis fields at comparable spatial scales is crucial to making this integrated modeling system a practical diagnostic tool for air quality research. FDDA applied through analysis nudging has been used for decades to provide this constraint in other models such as MM4, MM5, and WRF. The results shown here demonstrate that it also works quite well in MPAS-A. Comparison of MPAS-A simulations of January and July 2013 with and without FDDA demonstrates that unconstrained simulations deviate significantly from historical conditions in only a few days, while 
those constrained through analysis nudging follow historical conditions well in most situations. Due to surface-layer decoupling, analysis nudging applied only above the PBL was not able to constrain the development of excessively cold surface temperatures in Arctic areas during the January 2013 simulation period. However, this can be addressed with the use of land surface models that also employ FDDA. Further study is already underway at the U.S. EPA to determine the best strength with which to nudge temperature, humidity, and wind in MPAS-A and the levels of the atmosphere to best apply that nudging.

The target fields toward which MPAS-A state variables are nudged could come from a number of sources. Historical meteorological reanalysis products have previously been used for this purpose in regional and hemispheric modeling with WRF, and the results here suggest they can also be used with MPAS-A on the global scale. This study applied MPAS-A with a variable $92-25 \mathrm{~km}$ mesh with the refined region centered on North America. Target fields used here were based on the $1^{\circ} \times 1^{\circ}$ NCEP FNL reanalysis product. As such, there was not a great disparity in horizontal resolution between the simulations and the target fields where the MPAS-A mesh size was $92 \mathrm{~km}$. However, where the mesh was more refined, MPAS-A was capable of delivering additional horizontal detail, and the results shown here indicate weaker nudging may produce superior results, at least when nudging water vapor mixing ratio. Finally, adding FDDA did not disrupt the ability of MPAS-A simulations to conserve mass, and this is an important point when considering its use for air quality modeling.
Code and data availability. The MPAS-A model software used in this project is a subset of the complete Model for Prediction Across Scales (MPAS) developed by Los Alamos National Security, LLC (LANS) and the University Corporation for Atmospheric Research (UCAR), and distributed under a three-clause BSD license allowing distribution of original and derivative works under conditions that have been satisfied here. The full text of this BSD license can be found at http://mpas-dev.github.io/files/ documents/MPAS-DevelopersGuide.pdf (last access: 9 July 2018). MPAS-A model source codes used in this study are available in the Supplement and at https://doi.org/10.5281/zenodo.1101204 with all modified codes accompanied by their original codes. Run scripts used to prepare FDDA target fields are also included in the Supplement and at https://doi.org/10.5281/zenodo.1101204. The definition file for the $92-25 \mathrm{~km}$ computational mesh used in this study is too large for the Supplement, but it can be obtained from https://doi.org/10.5281/zenodo.1101204. Operational model global tropospheric analysis data used to initialize MPAS-A and to define FDDA target fields are available at https://doi.org/10.5065/D6M043C6 (NCEP/NWS/NOAA/U.S. Department of Commerce, 2000). The Atmospheric Model Evaluation Tool used in this study is available at https://www.cmascenter.org/ amet/ (last access: 9 July 2018). Observational data used within AMET were obtained from https://madis.noaa.gov/ (last access: 9 July 2018). 


\section{Appendix A}

The following describes Fortran code modifications made to define a vertical layer structure with fine resolution near the surface without the use of an extremely large number of layers. The basis for these changes was the MPAS-A model code originally published in the MPAS version 4.0 code release dated 22 May 2015. These changes are included in the MPAS model codes provided in the Supplement and at https://doi.org/10.5281/zenodo.1101204.

In src/core_init_atmosphere/mpas_init_atm_cases.F, make the following edits:

Replace line 2538 with the following:

real (kind = RKIND) :: r_earth, etavs, ztemp, zd, zt, gam, delt, str, grd, kfrac

Replace lines 2864 through 2870 with the following: write $\left(0,{ }^{*}\right)$ “*** Using custom layer definition ${ }^{* * *}$ ” $\operatorname{str}=3$.

$\operatorname{grd}=0.03$

$\mathrm{zt}=$ config_ztop

do $\mathrm{k}=1, \mathrm{nz}$

$\mathrm{kfrac}=\operatorname{real}(\mathrm{k}-1) / \operatorname{real}(\mathrm{nz} 1)$

$\mathrm{zw}(\mathrm{k})=\mathrm{zt} *((1-\operatorname{grd}) * \mathrm{kfrac} * * \mathrm{str}+\operatorname{grd} * \mathrm{kfrac})$

\section{Appendix B}

The following italicized text by Duda (2015) is a direct quote obtained from the MPAS GitHub site (https://git.io/vhJ1t, last access: 9 July 2018) which addresses a problem with sea ice being defined over land areas.

Description: Activate the "vertical_stage_in" package when config_init_case $==8$

The init_atmosphere core previously only activated packages to read in static fields when config_init_case $==7$ (and either config_vertical_grid or config_met_interp were true). However, for config_init_case $==8$, we need the landmask field for interpolating, e.g., sea ice. Since we may potentially need other static fields as well when creating surface update files, the simplest solution seems to be to simply read all static fields when config_init_case $==8$ by activating the vertical_stage_in package for this case.

The basis for these changes is the MPAS-A model code originally published in the MPAS version 4.0 code release dated 22 May 2015. The recommended correction has been made to the MPAS model codes provided in the Supplement and at https://doi.org/10.5281/zenodo.1101204. This correction was implemented by adding the following five lines of Fortran code after line 162 in src/core_init_atmosphere/mpas_init_atm_core_interface.F.

else if (config_init_case $==8$ ) then

vertical_stage_in $=$.true.

vertical_stage_out $=$.false.

met_stage_in $=$.false.

met_stage_out $=$.false. 
Supplement. The supplement related to this article is available online at: https://doi.org/10.5194/gmd-11-2897-2018-supplement.

Author contributions. OB modified the MPAS-A model to use a modified vertical layer structure and enable four-dimensional data assimilation, designed the simulations, analyzed the results, and led the development of the manuscript. RG and OB developed the Atmospheric Model Evaluation Tool to make it applicable for MPASA. HF modified the MPAS-A model to provide mass conservation accounting. JH modified the MPAS-A model to use special physics parameterizations for air-quality applications. All authors contributed to the editing of the manuscript.

Competing interests. The authors declare that they have no conflict of interest.

Acknowledgements. This research was performed while Hosein Foroutan held a National Research Council Research Associateship Award at the U.S. EPA. We thank Tanya Spero and Jon Pleim (U.S. EPA) for their internal review of the manuscript and providing constructive comments. The views expressed in this article are those of the authors and do not necessarily represent the views or policies of the United States Environmental Protection Agency.

Edited by: James R. Maddison

Reviewed by: Marek Wlasak and one anonymous referee

\section{References}

Anthes, R. A.: Data assimilation and initialization of hurricane prediction models, J. Atmos. Sci., 40, 702-719, 1974.

Anthes, R. A., Hsie, E.-Y., and Kuo, Y.-H.: Description of the Penn State/NCAR Mesoscale Model version 4 (MM4), NCAR Tech. Note NCAR/TN-282+STR, 66 pp., 1987.

Appel, K. W., Gilliam, R. C., Davis, N., Zubrow, A., and Howard, S. C.: Overview of the Atmospheric Model Evaluation Tool (AMET) v1.1 for evaluating meteorological and air quality models, Environ. Model. Softw., 26, 434-443, https://doi.org/10.1016/j.envsoft.2010.09.007, 2011.

Appel, K. W., Napelenok, S. L., Foley, K. M., Pye, H. O. T., Hogrefe, C., Luecken, D. J., Bash, J. O., Roselle, S. J., Pleim, J. E., Foroutan, H., Hutzell, W. T., Pouliot, G. A., Sarwar, G., Fahey, K. M., Gantt, B., Gilliam, R. C., Heath, N. K., Kang, D., Mathur, R., Schwede, D. B., Spero, T. L., Wong, D. C., and Young, J. O.: Description and evaluation of the Community Multiscale Air Quality (CMAQ) modeling system version 5.1, Geosci. Model Dev., 10, 1703-1732, https://doi.org/10.5194/gmd-10-1703-2017, 2017.

Bowden, J. H., Otte, T. L., Nolte, C. G., and Otte, M. J.: Examining interior grid nudging techniques using two-way nesting in the WRF model for regional climate modeling, J. Climate, 25, 28052823, https://doi.org/10.1175/JCLI-D-11-00167.1, 2012.

Bowden, J. H., Nolte, C. G., and Otte, T. L.: Simulation the impact of the large-scale circulation on the $2 \mathrm{~m}$ temperature and precipitation climatology, Clim. Dynam., 40, 1903-1920, https://doi.org/10.1007/s00382-012-1440-y, 2013.

Bullock Jr., O. R., Atkinson, D., Braverman, T., Civerolo, K., Dastoor, A., Davignon, D., Ku, J.-Y., Lohman, K., Myers, T. C., Park, R. J., Seigneur, C., Selin, N. E., Sistla, G., and Vijayaraghavan, K.: The North American Mercury Model Intercomparison Study (NAMMIS): Study description and model-to-model comparisons, J. Geophys. Res., 113, D17310, https://doi.org/10.1029/2008JD009803, 2008.

Bullock Jr., O. R., Atkinson, D., Braverman, T., Civerolo, K., Dastoor, A., Davignon, D., Ku, J.-Y., Lohman, K., Myers, T. C., Park, R. J., Seigneur, C., Selin, N. E., Sistla, G., and Vijayaraghavan, K.: An analysis of simulated wet deposition of mercury from the North American Mercury Model Intercomparison Study, J. Geophys. Res., 114, D08301, https://doi.org/10.1029/2008JD011224, 2009.

Bullock Jr., O. R., Alapaty, K., Herwehe, J. A., Mallard, M. S., Otte, T. L., Gilliam, R. C., and Nolte, C. G.: An observation-based investigation of nudging in WRF for downscaling surface climate information to $12-\mathrm{km}$ grid spacing, J. Appl. Meteor. Climatol., 53, 20-33, https://doi.org/10.1175/JAMC-D-13-030.1, 2014.

Byun, D. and Schere, K. L.: Review of the governing equations, computational algorithms, and other components of the Model-3 Community Multiscale Air Quality (CMAQ) Modeling System, Appl. Mech. Rev. 59, 51-77, https://doi.org/10.1115/1.2128636, 2006.

Chang, J. S., Brost, R. A., Isaksen, I. S. A., Madronich, S., Middleton, P., Stockwell, W. R., and Walcek, C. J.: A threedimensional Eulerian acid deposition model: Physical concepts and formulation, J. Geophys. Res., 92, 14681-14700, https://doi.org/10.1029/JD092iD12p14681, 1987.

Charney, J., Halem, M., and Jastrow, K.: Use of incomplete historical data to infer the present state of the atmosphere, J. Atmos. Sci., 26, 1160-1163, https://doi.org/10.1175/1520 0469(1969)026<1160:UOIHDT>2.0.CO;2, 1969.

Du, Q., Faber, V., and Gunzburger, M.: Centroidal Voronoi Tessellations: Applications and Algorithms, SIAM Rev., 41, 637-676, 1999.

Duda, M. G.: MPAS-Release, v4.0, available at: https://github.com/nickszap/MPAS-Release/commit/ 88f730142fc2ea04db12aa5e37f3337114e2ac45 (last access: 9 July 2018), 2015.

Grell, G. A., Dudhia, J., and Stauffer, D. R.: A description of the Fifth-Generation Penn State/NCAR Mesoscale Model (MM5), NCAR Tech. Note NCAR/TN-398+STR, 122 pp., 1995.

Hoke, J. E. and Anthes, R. A.: The initialization of numerical models by a dynamic-initialization technique, Mon. Weather Rev., 104, 1551-1556, https://doi.org/10.1175/1520 0493(1976)104<1551:TIONMB>2.0.CO;2, 1976.

Jacobson, M. Z. and Ginnebaugh, D. L.: Global-through-urban nested three-dimensional simulation of air pollution with a 13,600-reaction photochemical mechanism, J. Geophys. Res., 115, D14304, https://doi.org/10.1029/2009JD013289, 2010.

Mathur, R., Roselle, S., Young, J., and Kang, D.: Representing the effects of long-range transport and lateral boundary conditions in regional air pollution models, in: Air Pollution Modeling and Its Application XXII, edited by: Steyn, D., Builtjes, P., and Timmermans, R., Chap. 51, 303-308, https://doi.org/10.1007/97894-007-5577-2_51, 2014. 
Mathur, R., Xing, J., Gilliam, R., Sarwar, G., Hogrefe, C., Pleim, J., Pouliot, G., Roselle, S., Spero, T. L., Wong, D. C., and Young, J.: Extending the Community Multiscale Air Quality (CMAQ) modeling system to hemispheric scales: overview of process considerations and initial applications, Atmos. Chem. Phys., 17, 12449-12474, https://doi.org/10.5194/acp-17-124492017, 2017.

NCEP/NWS/NOAA/U.S. Department of Commerce: NCEP FNL Operational Model Global Tropospheric Analyses, continuing from July 1999, Research Data Archive at the National Center for Atmospheric Research, Computational and Information Systems Laboratory, https://doi.org/10.5065/D6M043C6 (last access: 1 March 2016), 2000 (updated daily).

NRC: The atmospheric sciences: Entering the twenty-first century, National Academy Press, Washington, DC, 384 pp., https://doi.org/10.17226/6021, 1998.

NRC: Global sources of local pollution: an assessment of longrange transport of key air pollutants to and from the United States, National Academy Press, Washington, DC, 234 pp., https://doi.org/10.17226/12743, 2010.

Otte, T. L., Nolte, C. G., Otte, M. J., and Bowden, J. H.: Does nudging squelch the extremes in regional climate modeling?, J. Climate, 25, 7046-7066, https://doi.org/10.1175/JCLI D 12$00048.1,2012$.

Schere, K., Flemming, J., Vautard, R., Chemel, C., Colette, A., Hogrefe, C., Bessagnet, B., Meleux, F., Mathur, R., Roselle, S., Hu, R.-M., Sokhi, R. S., Rao, S. T., and Galmarini, S.: Trace gas/aerosol boundary concentrations and their impacts on continental-scale AQMEII modeling domains, Atmos. Environ., 53, 38-50, https://doi.org/10.1016/j.atmosenv.2011.09.043, 2012.
Skamarock, W. C. and Klemp, J. B.: A time-split nonhydrostatic atmospheric model for weather research and forecasting applications, J. Comput. Phys., 227, 3465-3485, https://doi.org/10.1016/j.jcp.2007.01.037, 2008.

Skamarock, W. C., Klemp, J. B., Duda, M. G., Fowler, L. D., and Park, S.-H.: A multiscale nonhydrostatic atmospheric model using centroidal Voronoi tesselations and C-grid staggering, Mon. Weather Rev., 140, 3090-3105, https://doi.org/10.1175/MWRD-11-00215.1, 2012.

Stauffer, D. R. and Seaman, N. L.: Use of four-dimensional data assimilation in a limited-area model, Part I: Experiments with synoptic-scale data, Mon. Weather Rev., 118, 1250-1277, https://doi.org/10.1175/15200493(1990)118<1250:UOFDDA>2.0.CO;2, 1990.

Tudor, M. and Termonia, P.: Alternative formulations for incorporating lateral boundary data into limitedarea models, Mon. Weather Rev., 138, 2867-2882, https://doi.org/10.1175/2010MWR3179.1, 2010.

Warner, T. T., Peterson, R. A., and Treadon, R. E.: A tutorial on lateral boundary conditions as a basic and potentially serious limitation to regional numerical weather prediction, B. Am. Meteorol. Soc., 78, 2599-2617, https://doi.org/10.1175/1520 0477(1997)078<2599:ATOLBC>2.0.CO;2, 1997. 